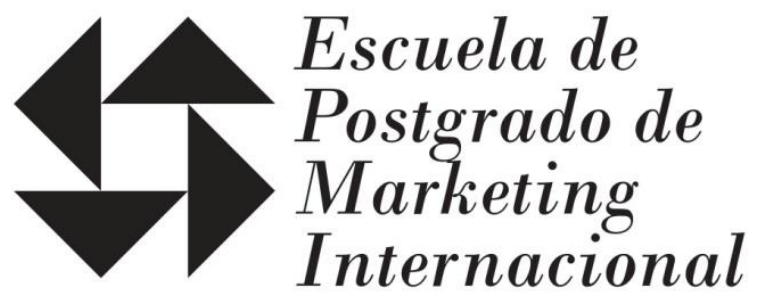

\title{
Plan de Marketing Internacional para la Exportación de Servicios de Diseño Gráfico
}

\author{
Trabajo Científico libre para la obtención del grado de \\ Magister en Marketing Internacional de la \\ Escuela de Postgrado de Marketing Internacional \\ Facultad de Ciencias Económicas \\ - Universidad Nacional de La Plata -
}

Director de Tesis:

Presentado por

Prof. José Pedro Pagano

Érico Almeida

Fecha de entrega: 01 - octubre - 2018 
Dedico este trabajo a Carmen Woichikowski (in memorian), que me ha enseñado que la educación es el movimiento de la oscuridad a la luz. 
Quiero expresar mis más sinceros agradecimientos a todas las personas que me brindaron con sus conocimientos, su colaboración, y su ayuda durante la realización de esta tesis y a lo largo de toda la maestría.

Especialmente a mi familia: mi madre y mi hermana, por siempre obligarme a terminar, por el apoyo en los momentos difíciles, por la constante motivación y por no dejar de creer en mí mismo de lejos, lo que me permitió concluir esta etapa.

A mis amigos en Brasil y Argentina, por su tiempo, sus palabras de aliento y sus contribuciones a mi investigación.

A Carmen Woichikowski (in memoriam) y Charles Hyczy, de ICEPEM, por todo el apoyo, por creer en mi trabajo y por incentivar mi desarrollo personal y profesional.

A mis colegas de la Universidad Nacional de La Plata, por compartir su tiempo, experiencias y conocimientos conmigo durante mis estudios.

A mi orientador José Pedro Pagano, por compartir sus ricas experiencias profesionales y también a todos los profesores, que contribuyeron de manera significativa con sus conocimientos al desarrollo de esta tesis.

Agradezco en especial a este país, Argentina, que me ha acogido y brindó lo mejor de sí para la evolución de mi conocimiento y con eso me he convertido en una persona mejor. 
No somos constreñidos por nada, sino por nuestra propia ignorancia.

Yuval Noah Harari 
Plan de Marketing Internacional para la

Exportación de Servicios de Diseño Gráfico.

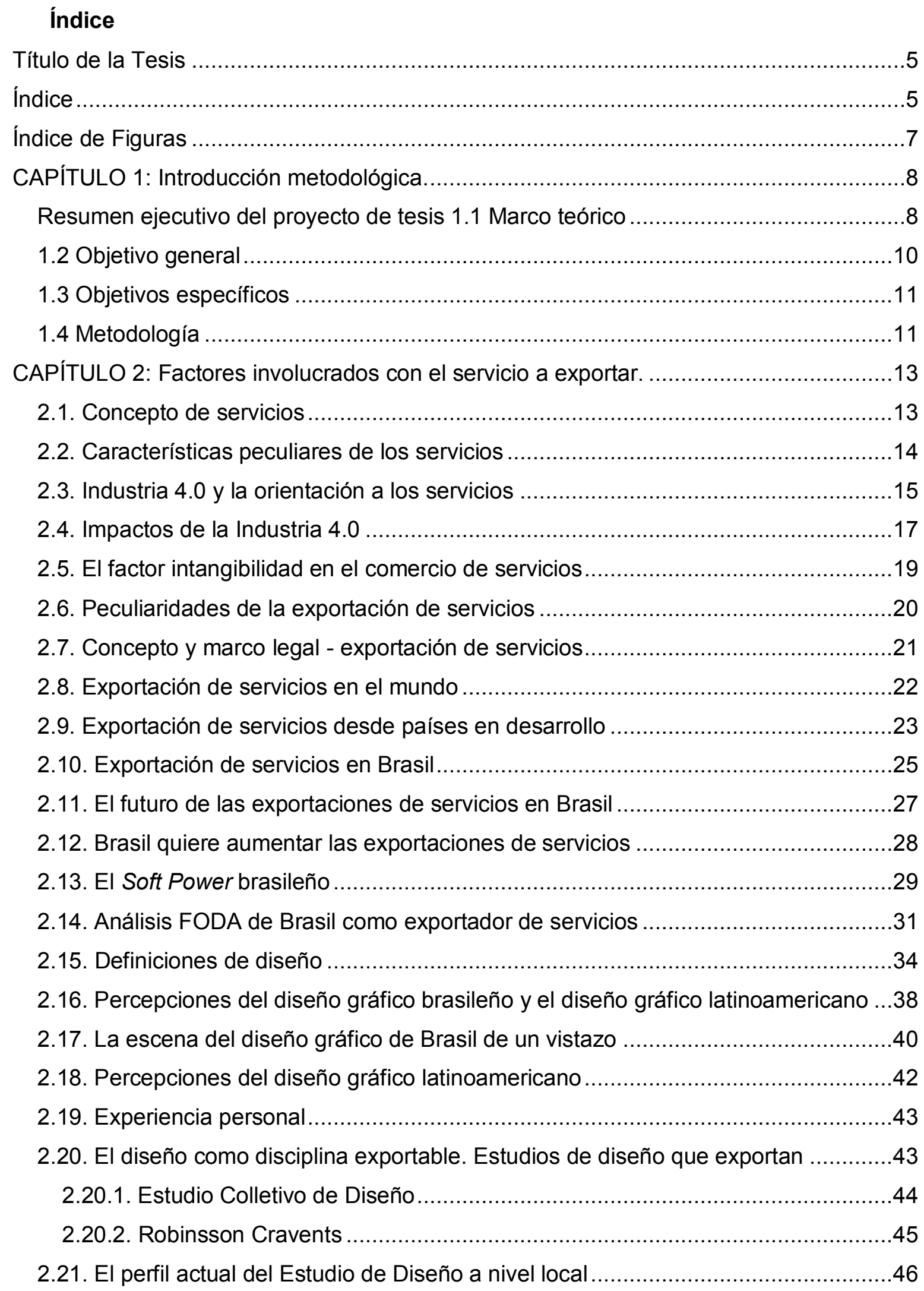


CAPÍTULO 3: Programas de acción necesarios para la exportación de servicios de diseño gráfico

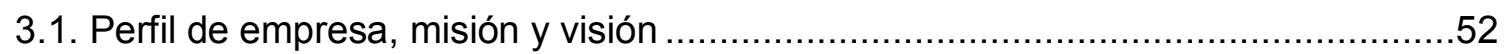

3.2. Objetivo general y objetivos específicos del Plan de Marketing............................54

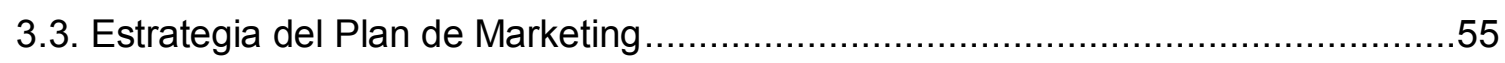

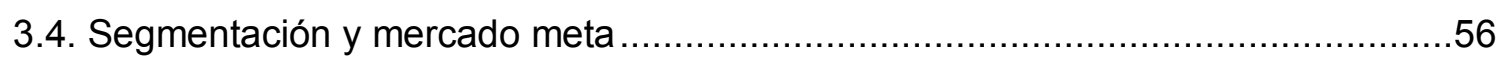

3.4.1. Exportaciones de servicios de Brasil a EE.UU ...........................................58

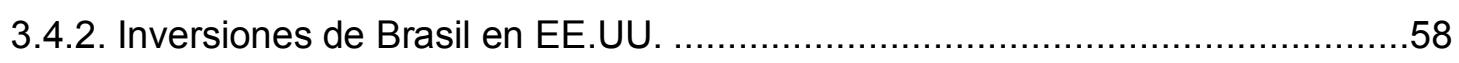

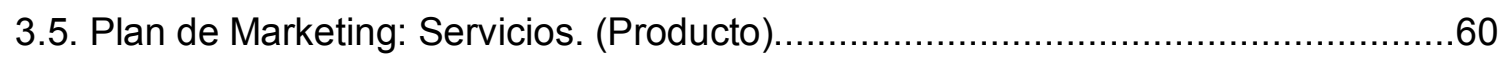

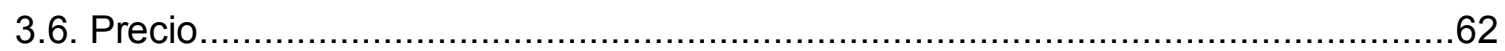

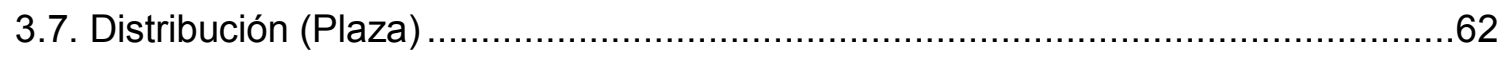

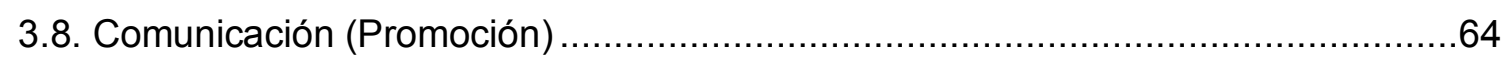

CAPÍTULO 4: Sistema de control para supervisar el progreso del plan de marketing

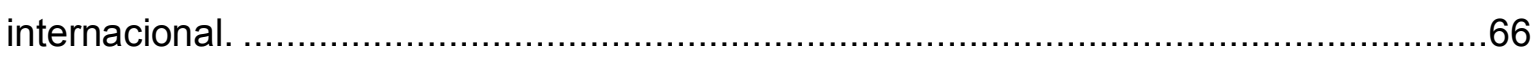

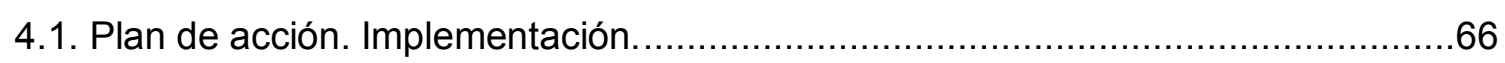

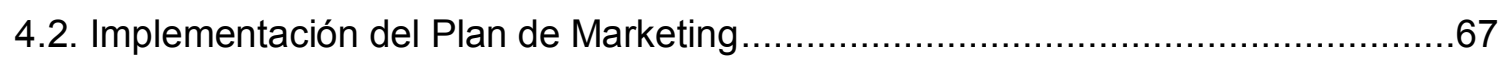

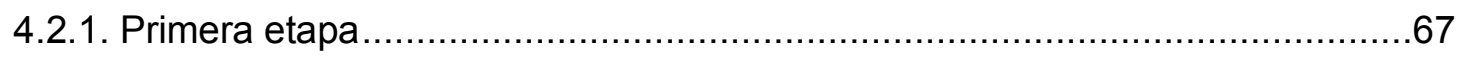

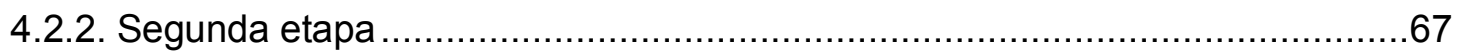

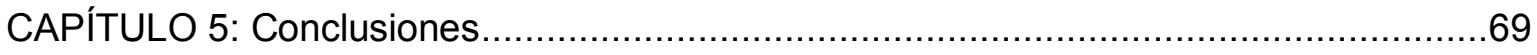

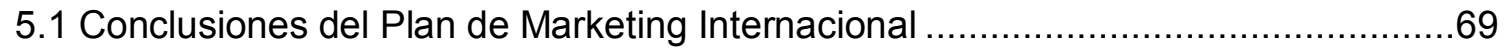

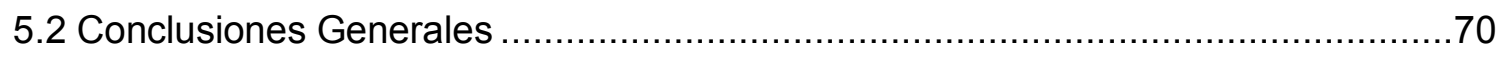

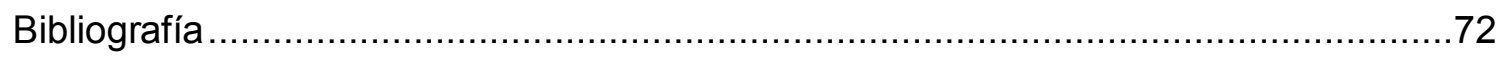

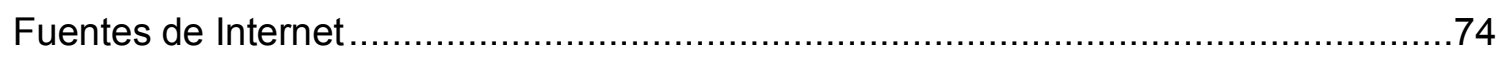

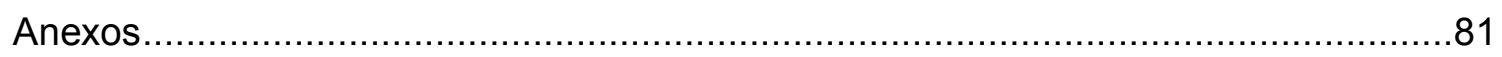

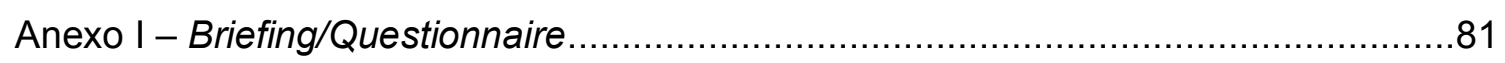

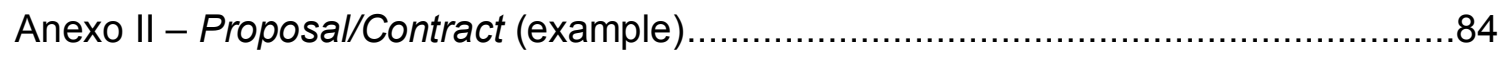

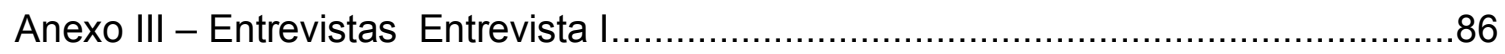

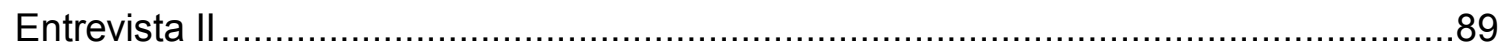




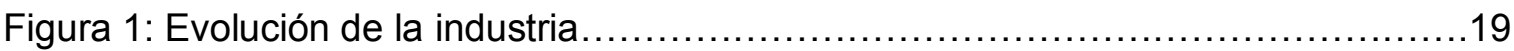

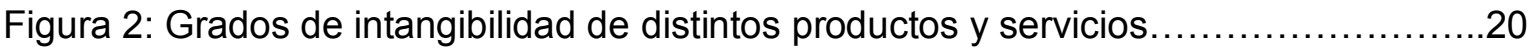

Figura 3: Matriz de clasificación según las peculiaridades de los servicios $\ldots \ldots \ldots \ldots \ldots \ldots . \ldots 21$

Figura 4: Evolución de la exportación de servicios en el mundo ..........................23

Figura 5: Evolución de la exportación e importación de servicios en Brasil de 1995 hasta 2016 


\section{CAPÍTULO 1: Introducción metodológica.}

\section{Resumen ejecutivo del proyecto de tesis}

\subsection{Marco teórico}

Con la velocidad con que la mayoría de los sectores de la economía evolucionan, así como la presencia de una competencia creciente y cada vez más agresiva, los directores y administradores de las empresas que actúan en otros países necesitan de una gran capacidad de planificación y posterior ejecución de acciones que puedan contribuir al crecimiento y desarrollo de sus organizaciones. El más eficaz medio de ejecución de estrategias planificadas de negocios en el mundo globalizado en que vivimos pasa por la elaboración de un Plan de Marketing Internacional (PMI).

Jorge Garcia Mallo ${ }^{1}$ acuerda cuán importante es para una empresa que actúa o pretende actuar en otros países, la preparación y aplicación de un plan de marketing internacional por fases, a través del estudio del entorno internacional, de la competencia y de las aptitudes de la organización para confrontarse a los mercados extranjeros, así como la instauración de unos propósitos cuantificables y de una sucesión de operaciones, labores y políticas imprescindibles para conseguir y adquirir esos propósitos.

María del Sol García Fernández ${ }^{2}$ añade que el plan de marketing internacional debe ser una parte más del plan de marketing general, por lo que debe ser doblemente coherente: primero con el plan de marketing de la empresa y segundo con el plan estratégico global de ésta.

Ya la autora Luisa María Carpintero Viejo ${ }^{3}$, enmarca que los objetivos relacionados con los mercados internacionales, se pueden resumir en tres: crecimiento, rentabilidad o consolidación. Estos objetivos deben ser alcanzables, medibles, realistas, motivadores y deben estar definidos con claridad y precisión.

\footnotetext{
${ }^{1}$ Mallo, J. G. (2015). UF1783 - Plan e informes de marketing internacional. Certificado de Profesionalidad. Marketing y Compraventa Internacional (COMM0110). ( $1^{\mathrm{a}}$ ed) Madrid: Ed. Elearning.

${ }^{2}$ Fernández, M. S. G. (2014). UF1783: Plan e informes de marketing internacional. (1 $\left.{ }^{\mathrm{a}} \mathrm{ed}\right)$ Antequera, España: Ed. IC Editorial.

${ }^{3}$ Viejo, L. M. C. (2014). UF1783: Plan e informes de marketing internacional. (1 ${ }^{\mathrm{a}}$ ed) Madrid: Ed.

Paraninfo.
} 
La exportación de servicios es uno de los fenómenos más dinámicos de la economía internacional contemporánea. Algunos servicios profesionales relacionados con la salud, educación, servicios jurídicos y contables, investigación y desarrollo, publicidad y diseño gráfico han ganado una proporción mucho mayor con el paso del tiempo, ya que antes se prestaban prácticamente dentro de las fronteras de cada país y hoy día son comercializables con frecuencia en el ámbito mundial.

La constante expansión de la velocidad de transmisión de datos por internet tiene impacto directo en la oferta y demanda de servicios. La información globalmente disponible fortalece el reconocimiento de las marcas, haciendo que la preparación y la mirada atenta del proveedor de servicios para el comercio internacional sea una cuestión de supervivencia.

Todos estos aspectos, además del flujo constante y creciente de personas entre los diversos países, son pilares que hacen los servicios cada vez más transaccionales en el comercio exterior. Según datos del Centro de Comercio Internacional ${ }^{4}$, agencia multilateral que tiene un mandato conjunto con la Organización Mundial del Comercio (OMC) y las Naciones Unidas (ONU), las exportaciones mundiales de servicios comerciales, que incluyen los servicios de turismo, transportes, telecomunicaciones, seguros y pensiones, servicios financieros, servicios de gobierno, tajas por el uso de propiedad intelectual, servicios de mantenimiento y reparos, construcción y los servicios profesionales, o sea, los realizados por trabajadores independientes o empresas especializadas en hacer cierto tipo de trabajo, fueron responsables por el movimiento de 4,83 billones de dólares en 2016 , un aumento del 6,9\% con respecto al 2012. De este valor total, solamente las exportaciones de servicios profesionales representaran 1,05 billones de dólares, un aumento impresionante del 16,5\% con relación al 2012.

Arti Grover Goswami, Aaditya Mattoo y Sebastián Sáez ${ }^{5}$, afirman que las últimas dos décadas han visto importantes cambios con los países en desarrollo emergiendo como exportadores de servicios. Las exportaciones de servicios resultan especialmente

\footnotetext{
${ }^{4}$ International Trade Center (2017). Trade Map - International Trade Statistics - List of exported services for the selected service. Recuperado 31 de diciembre de 2017 de https://www.trademap.org/tradestat/Service_SelService_TS.aspx?nvpm=1|||||||S00|1|3|1|2|2|1|5|1|1 ${ }^{5}$ Goswami, A. G., Mattoo, A., Saez S. (2012). Exporting Services: A Developing Country Perspective (Trade and Development). ( $1^{\mathrm{a}}$ ed) Washington: World Bank Publications.
} 
relevantes para estos países, ya que las mismas contribuyen de manera significativa a 10 la creación de puestos de trabajo y así al desarrollo de manera general.

Algunos países han aprovechado los desarrollos tecnológicos que facilitan el comercio de servicios a través de las fronteras. La autora Carolina Zimmer ${ }^{6}$ explica que con la tendencia del aumento de las exportaciones de servicios, el gobierno de Brasil ha creado una serie de herramientas para el perfeccionamiento de las acciones de estímulo, formulación, acompañamiento y evaluación de las políticas públicas y estrategias empresariales volcadas a la exportación de servicios.

En este caso en particular se pretende comercializar en el exterior servicios de diseño gráfico, disciplina que trabaja principalmente con recursos estéticos, visuales, comunicacionales y estratégicos.

Vale comentar que el trabajo del diseñador gráfico es básicamente poner una significación visual en marcas, empresas y productos, ya que estos conquistan a las personas a medida que les significa algo. Así que el autor está de acuerdo con Drew de Soto $^{7}$ que dice que el diseñador es un artista comercial, entonces sus diseños deben ser comerciales. De esta manera es un servicio fundamental para el éxito de cualquier emprendimiento en el mundo globalizado en que vivimos, por lo que se ve la oportunidad de expandir el campo de actuación profesional hacia el mundo.

El foco de trabajo y base para el desarrollo del plan de marketing internacional será el estudio de diseño gráfico del autor de la tesis, que incluso ya ha ejecutado algunos trabajos hacia el exterior de manera fortuita y tiene como referencia a algunos colegas de profesión que ya hacen la exportación de sus proyectos creativos de manera continua y estructurada.

\subsection{Objetivo general}

Planear los lineamientos estratégicos para la exportación de servicios de diseño gráfico.

\footnotetext{
${ }^{6}$ Zimmer C. (2014). Importação e Exportação de Serviços e Intangíveis. (1ª ed) São Paulo: Ed. Fiscosoft.

7 Soto, D. (2012). Know Your Onions - Graphic Design: How to Think Like a Creative, Act like a Businessman and Design Like a God Paperback. ( $1^{\mathrm{a}}$ ed) Amsterdam: Bis Publishers.
} 
- Determinar los factores involucrados con el servicio a exportar.

- Delinear los programas de acción necesarios para la exportación de servicios de diseño gráfico.

- Definir un sistema de control para supervisar el progreso del plan de marketing internacional.

\subsection{Metodología}

En el presente trabajo, se realizará un tipo de investigación descriptiva para conocer en profundidad el contexto actual cuando el tema es plan de marketing internacional volcado a la exportación de servicios.

Se recurrirá a fuentes primarias, buscando a datos cualitativos realizando entrevistas basadas en preguntas disparadoras a representantes de instituciones con conocimiento y experiencia en planeamiento de marketing internacional con foco a la exportación de servicios, como es el caso de Apex Brasil (Agencia Brasilera de Promoción de Exportaciones e Inversiones) y SEBRAE (Servicio Brasilero de Apoyo a la Micro y Pequeña Empresa). Además, se va a definir claramente con qué perfil se posiciona el estudio del autor de la tesis como empresa exportadora de servicios de diseño gráfico.

También se emplearán fuentes secundarias que brindan datos cuantitativos y estadísticos sobre la expansión de la exportación de servicios en Brasil a través de organismos internacionales, como el Banco Mundial y la Organización Mundial del Comercio (OMC), y nacionales como el Banco de Brasil, el MDIC (Ministerio de la Industria, Comercio Exterior y Servicios) y por la RFB (Receita Federal Brasileira), órgano responsable por la recaudación federal de Brasil.

Aún se complementará con medios de comunicación especializados que cuentan con información sobre casos similares existentes en el mercado de forma a analizar cómo es el funcionamiento de dicho modelo de negocio.

Por último, se hará uso de la bibliografía referente al diseño gráfico para enmarcarlo como servicio exportable.

Así que la captación de datos será de tipo estructurado de acuerdo a los indicadores 
previamente establecidos, y semiestructurado, debido a que las entrevistas en profundidad serán entrevistas semiestructuradas, ya que seguirán un guía, pero los entrevistados tendrán gran libertad para responder a las preguntas. Los datos serán analizados con la aplicación del modelo descriptivo propuesto en conjunto con la base teórica y al comprobar si es posible cumplir con los objetivos del plan de marketing internacional.

Las técnicas utilizadas de muestreo probabilístico serán sistemáticas, ya que los elementos del muestreo serán seleccionados con foco específico en la exportación de servicios profesionales. 


\section{CAPÍTULO 2: Factores involucrados con el servicio a exportar.}

En el presente capítulo se discutirá acerca de informaciones importantes concernientes a la exportación de servicios, mostrando desde la diferencia con respecto a la exportación de bienes de consumo hasta las leyes y acuerdos internacionales relacionados con el asunto. Se prestará especial atención a los servicios foco de esta tesis (diseño gráfico).

Se abordará el contexto actual de la exportación de servicios en el mundo, en países en desarrollo, y finalmente en Brasil. Se transcurrirá con respecto a los rasgos del perfil nacional exportador de servicios junto a sus destinos frecuentes y recomendados, para luego concluir en un análisis FODA sobre el contexto actual y cómo es para Brasil frente a este contexto.

También en este capítulo, vamos a trabajar con una breve presentación del sector foco de esa tesis, el diseño gráfico, para entender los criterios necesarios para establecer una empresa de diseño con un perfil de exportación a medio y largo plazo. Vamos a discutir sobre el valor del diseño en el contexto brasileño y cómo el mundo ve el diseño "Made in Brazil".

\subsection{Concepto de servicios}

Antiguamente se creía que no era posible exportar servicios, a no ser ciertos tipos de servicios profesionales, como por ejemplo los de ingeniería y consultoría. Sin embargo, la globalización ha hecho que la exportación de servicios no sólo sea posible, sino que en algunos sectores sea muy fácil. La revolución en las comunicaciones y en la tecnología de la información permitió el acceso de proveedores de servicios a otras partes del mundo y amplió increíblemente las posibilidades de exportación de los más variados tipos de servicios. El ejemplo más típico: el comercio electrónico. Cualquier persona puede comprar libros, DVDs, equipos electrónicos, ropa, perfumes y una infinidad de otros productos en tiendas virtuales de otros países, siempre que tenga acceso por ordenador y una tarjeta de crédito en mano. ${ }^{8}$

\footnotetext{
${ }^{8}$ Guia Básico para a Exportação de Serviços - Versão Revisada - Julho 2017. Recuperado el 31 de julio de 2018 de http://www.mdic.gov.br/images/REPOSITORIO/scs/decin/Guia_B\%C3\%A1sico/Guia_B\%C3\%A1si co_-versao_2017.pdf
} 
Según el autor Arti Grover Goswami, ${ }^{9}$ esto no es válido para todos los servicios. Todavía existen servicios que sólo pueden ser prestados con la presencia física del proveedor en el lugar específico en que se encuentra el cliente. Ejemplos son los servicios de construcción, los servicios de peluquería y los de lavado de ropa, entre otros. En estos casos, necesariamente, la exportación exige el desplazamiento físico de personas. Hay también otros casos de prestación de servicios que exigen que el exportador tenga activos en el país de destino de la exportación, como es el caso de tiendas físicas y restaurantes. Sin embargo, las facilidades actuales y la caída en los costos de viajes internacionales hicieron posible que los prestadores de servicios se involucren mucho más profundamente con actividades internacionales.

\subsection{Características peculiares de los servicios}

Para el Sebrae - Servicio Brasileño de Apoyo a las Micro y Pequeñas Empresas ${ }^{10}$, los servicios difieren de los productos en cuatro aspectos principales: inseparabilidad, intangibilidad, perecibilidad y variabilidad, como se describe a continuación:

\section{Inseparabilidad}

La prestación y el consumo de la mayoría de los servicios son inseparables, es decir, se pueden consumir mientras se están produciendo. Esta característica significa que el consumo se da en el propio proceso de entrega del servicio.

\section{Intangibilidad}

Los servicios no pueden ser tocados, sentidos, olfateados o saboreados. Ellos pueden utilizar objetos físicos para ser prestados, pero ellos mismos no son tangibles.

\section{Perecedero}

En muchos casos, los servicios son producidos y consumidos simultáneamente, no pudiendo ser almacenados.

\section{Variabilidad}

\footnotetext{
${ }^{9}$ Goswami, A. G., Mattoo, A., Saez S. (2012). Exporting Services: A Developing Country Perspective (Trade and Development). ( $1^{\text {a }}$ ed) Washington: World Bank Publications.

${ }^{10}$ Sebrae - Como Exportar Serviços: Características e

Desafios. Recuperado el 22 de Julio de 2018 de https://bibliotecas.sebrae.com.br/chronus/ARQUIVOS_CHRONUS/bds/bds.nsf/2D154BF86547815 78325784500091797/\$File/NT000453DE.pdf
} 
Como la mayoría de los servicios son prestados por personas para otras personas, esto significa que el cliente y el proveedor del servicio deben interactuar. Así, el resultado del servicio depende del resultado de esa interacción y de su percepción por parte del consumidor. Cuando los seres humanos interactúan, los resultados muestran gran variabilidad y no son fáciles de predecir.

La inseparabilidad es observable cuando tomamos un taxi en la calle, por ejemplo. El servicio pasa a ser prestado cuando uno entra en el vehículo y se desplaza hasta la dirección donde desea llegar. No hay como separarlo en partes distintas de adquisición y consumo, como es posible hacer con un libro, en el que el consumidor compra el libro en una librería y lo lee posteriormente, en su casa.

Esta característica trae varias implicaciones para las empresas prestadoras de servicio, entre las cuales se destacan: La producción masiva de los servicios es difícil, tal vez imposible. Por lo tanto, no es posible obtener economías significativas con la centralización de las operaciones, ya que los servicios deben ser producidos de forma conveniente para los clientes, en el momento y en el lugar en que los solicitan ${ }^{11}$.

Otro punto es que la calidad de los servicios depende fuertemente de lo que sucede durante su prestación, es decir, en el momento del encuentro con los clientes. Esto significa que los proveedores de servicios deben probar su excelencia cada vez que se presta el servicio.

Aunque todo el proceso de venta, independiente de tratarse de bienes o servicios, posee cierto grado de intangibilidad, esa característica es aún más marcada cuando se habla de servicios.

\subsection{Industria 4.0 y la orientación a los servicios}

Con el surgimiento de la industria 4.0, o Cuarta Revolución Industrial, que es una expresión que engloba algunas tecnologías para automatización e intercambio de datos y utiliza conceptos de Sistemas Ciber-físicos, Internet de las Cosas y Computación en Nube, esa intangibilidad presente en el acto de compra de productos físicos tiende a aumentar, además del comercio en general orientarse cada vez más al perfil del

\footnotetext{
${ }^{11}$ Sebrae - Como Exportar Serviços: Características e Desafios. Recuperado el 22 de Julio de 2018 de https://bibliotecas.sebrae.com.br/chronus/ARQUIVOS_CHRONUS/bds/bds.nsf/2D154BF86547815 78325784500091797/\$File/NT000453DE.pdf
} 
prestador de servicios. La tendencia es que la calidad de cualquier relación comercial, 16 así como ya ocurre en la prestación de servicios, dependerá fuertemente de lo que sucede durante el proceso, o sea, en el momento del encuentro con los clientes. Las demandas en investigación y desarrollo también ofrecerán oportunidades para profesionales técnicamente capacitados, con formación multidisciplinaria para comprender y trabajar con la variedad de tecnología que compone una fábrica inteligente.

El fundamento básico de la industria 4.0 implica que conectando máquinas, sistemas y activos, las empresas podrán crear redes inteligentes a lo largo de toda la cadena de valor que pueden controlar los módulos de producción de forma autónoma. Es decir, así como la toma de decisiones y personalizaciones para clientes distintos que tenemos hoy en un proceso de prestación de servicios, las fábricas inteligentes tendrán capacidad y autonomía para adaptarse a los requisitos y cambios no planificados en la producción, como programar mantenimientos y preveer fallas en los procesos.

Existen cinco principios para el desarrollo e implementación de la industria 4.0, que definen los sistemas de producción inteligentes que tienden a surgir en los próximos años. Son ellos:

Capacidad de operación en tiempo real: Consiste en la adquisición y tratamiento de datos de forma prácticamente instantánea, permitiendo la toma de decisiones en tiempo real.

Virtualización: Las simulaciones ya se utilizan actualmente, así como los sistemas de supervisión. Sin embargo, la industria 4.0 propone la existencia de una copia virtual de las fábricas inteligentes. Permitiendo la trazabilidad y monitoreo remoto de todos los procesos a través de los numerosos sensores dispersos a lo largo de la planta.

Descentralización: La toma de decisiones puede ser hecha por el sistema ciber-físico de acuerdo con las necesidades de la producción en tiempo real. Además, las máquinas no sólo recibirán comandos, sino que también podrán proporcionar información sobre su ciclo de trabajo. Luego, los módulos de la fábrica inteligente trabajarán de forma descentralizada para perfeccionar los procesos de producción.

Modularidad: Producción de acuerdo con la demanda, acoplamiento y desacoplamiento de módulos en la producción. Lo que ofrece flexibilidad para cambiar las tareas de las máquinas fácilmente. 
Orientación a servicios: Utilización de arquitecturas de software orientadas a servicios aliado al concepto de Internet of Services. Según Steve Krug, autor del libro volcado al diseño digital "No me hagas pensar", aquí vale comentar cuán importante será el trabajo de un campo específico del diseño: el desarrollo de patrones visuales orientados al digital, o diseño de interfaz (también llamado User Interface Design o simplemente UI Design). Este es el medio por el cual una persona interactúa y controla un dispositivo, software o aplicación. Este control se puede hacer mediante botones, menúes y cualquier elemento que proporcione una interacción entre el dispositivo y el usuario. ${ }^{12}$

Krug añade que un buen diseño de interfaz anticipa las necesidades del usuario y garantiza que contenga elementos de fácil acceso y uso, proporcionando lo que se llama experiencia de usuario friendly, es decir, una experiencia que es amigable y que no causa frustraciones al usuario.

Es importante entender que la interfaz de usuario no es sólo acerca de cómo una aplicación o dispositivo se parece, ni qué colores o formas lo compone. Ul es acerca de cómo funciona y cómo se realizará la interacción, yendo mucho más allá de la apariencia que este producto tiene.

\subsection{Impactos de la Industria 4.0}

Según el DFKI - Deutsches Forschungszentrum für Künstliche Intelligenz ${ }^{13}$, (Centro Alemán de Investigación para Inteligencia Artificial), uno de los mayores impactos causados por la industria 4.0 será un cambio que afectará al mercado como un todo. Consiste en la creación de nuevos modelos de negocios. En un mercado cada vez más exigente, muchas empresas ya buscan integrar al producto necesidades y preferencias específicas de cada cliente. La personalización previa del producto por parte de los consumidores, como si estuviéramos hablando de un servicio, tiende a ser una variable más en el proceso de manufactura. Las fábricas inteligentes serán capaces de llevar la personalización de cada cliente en consideración, adaptándose a las preferencias.

\footnotetext{
${ }^{12}$ Krug, S. (2014). Don't Make Me Think, Revisited. A Common Sense Approach to Web Usability. $\left(1^{\text {a }}\right.$ ed) Indianapolis: Ed. New Riders.

${ }^{13}$ DFKI - German Research Center for Artificial Intelligence. Recuperado el 22 de Julio de 2018 de https://www.dfki.de/web
} 
El autor del libro "La Cuarta Revolución Industrial" ${ }^{14}$, Klaus Schwab, comenta que un 18 punto que será sacudido por esta nueva revolución será la investigación y desarrollo en los campos de seguridad en T.I., confiabilidad de la producción e interacción máquinamáquina. La tecnología debe desarrollarse continuamente para hacer viable la adaptación de empresas a este nuevo estándar de industria que está surgiendo.

Los profesionales también necesitarán adaptarse, pues con fábricas aún más automatizadas nuevas demandas surgirán mientras algunas dejarán de existir. Los trabajos manuales y repetitivos ya vienen siendo reemplazados por mano de obra automatizada, y con la industria 4.0 eso tiende a continuar. Por otro lado, las demandas en investigación y desarrollo ofrecerán oportunidades cada vez más concretas.

La tendencia es clara: los fabricantes necesitan pensar en su modelo de negocio con Internet de las Cosas Industriales (IloT) o Industria 4.0 y preguntar cómo un producto puede convertirse en un "servicio" con un flujo de ingresos a largo plazo.

En resumen, Schwab ${ }^{15}$ dice que cada industria podrá beneficiarse de diferente manera de la cuarta revolución industrial, con beneficios basados en:

- El internet de las cosas;

- En la intercomunicación de todos sus procesos y departamentos a través de internet;

- En la virtualización y simulación de procesos;

- En la medición y gestión de la energía y sus costos en tiempo real.

Todo puede ser monitoreado por sus dispositivos fijos o móviles con la finalidad de generar información valiosa que puede utilizarse para hacer la industria más eficiente y productiva, convirtiéndola así en una fábrica inteligente.

La industria 4.0, por ejemplo, puede ofrecer servicios de personalización de productos directamente al cliente a través de internet. El cliente puede generar su producto desde su casa, y la industria pueda producirlo automáticamente desde sus instalaciones, para luego ser distribuido y entregado.

La figura a seguir enseña de manera visual la evolución de la industria:

\footnotetext{
${ }^{14}$ Schwab, K. (2016). A Quarta Revolução Industrial. (1ª ed) São Paulo: Ed. Edipro.

15 Schwab, K. (2016). A Quarta Revolução Industrial. (1ª ed) São Paulo: Ed. Edipro.
} 
Figura 1: Evolución de la industria.

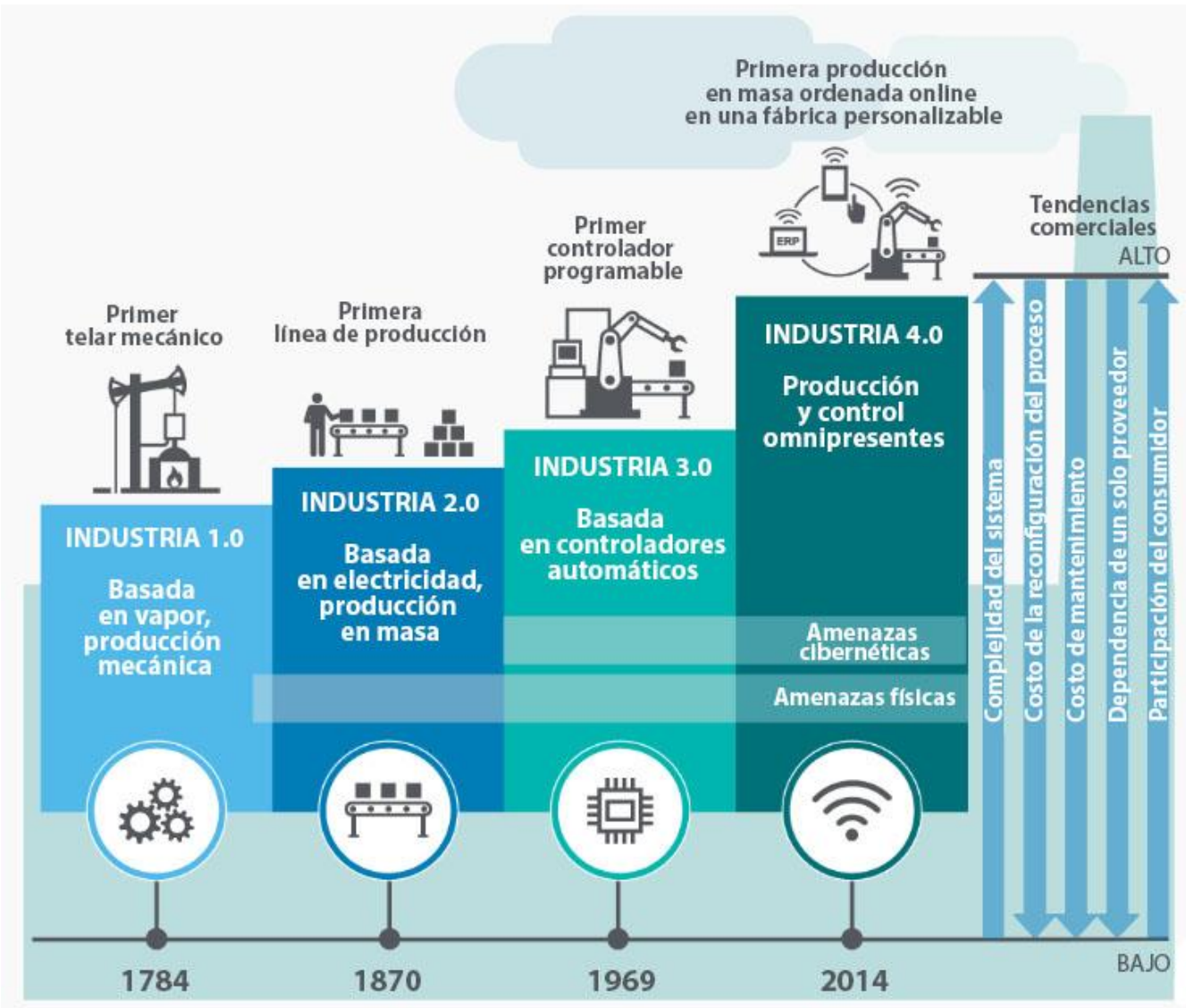

Fuente: Schwab, K. (2016). A Quarta Revolução Industrial. (1ª ed) São Paulo: Ed. Edipro.

Así que no importa más si estamos hablando de un producto o un servicio. Queda claro cuán importante es la adaptación constante y la atención personalizada a los clientes cada vez más exigentes y en constante cambio de gustos y opiniones en el mundo ultra conectado de hoy día.

\subsection{El factor intangibilidad en el comercio de servicios}

Aún sobre el factor intangibilidad, algunos servicios tradicionales como seguros y transportes son casi enteramente intangibles, y bienes como automóviles y vestuarios poseen muchos matices de intangibilidad como, por ejemplo, pueden ser probados o experimentados antes de ser comprados. El cuadro siguiente retrata un conjunto de productos, dispuestos en secuencia de intangibilidad creciente, según el Shostack Journal of Marketing: 
Figura 2: Grados de intangibilidad de distintos productos y servicios.

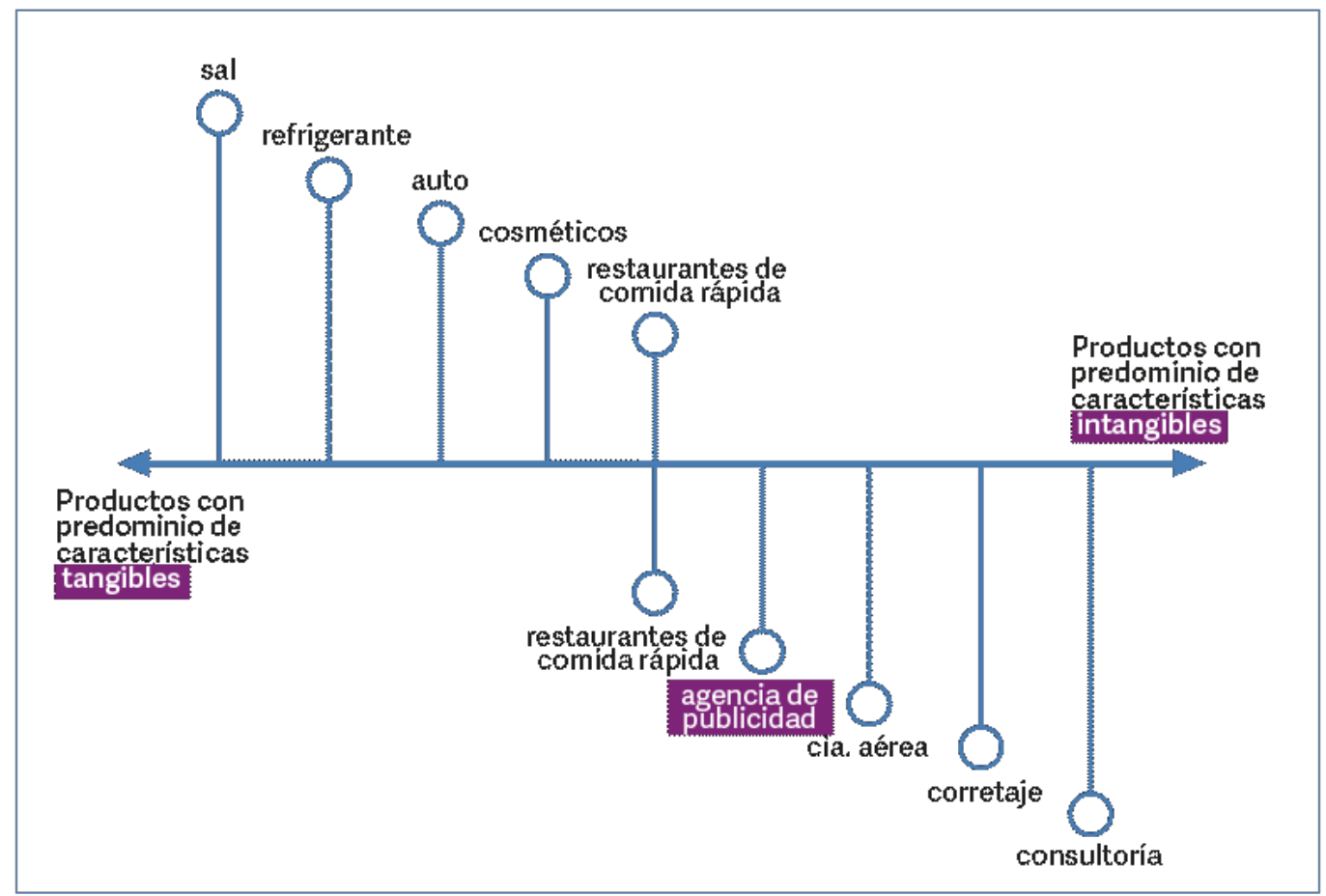

Fuente: Sebrae - Como Exportar Serviços: Características e Desafios. Adaptado de Shostack, Journal of Marketing, vol. 41,pp. 73-80. Recuperado el 22 de Julio de 2018 de https://bibliotecas.sebrae.com.br/chronus/ARQUIVOS_CHRONUS/bds/bds.nsf/2D154BF8 654781578325784500091797/\$File/NT000453DE.pdf

\subsection{Peculiaridades de la exportación de servicios}

Para facilitar la identificación de las diferentes formas de internacionalización de los servicios, dependiendo de si los mismos son separables (característica de inseparabilidad de los servicios previamente discutida) y si exigen mano de obra o capital para su internacionalización, se tiene la siguiente matriz de clasificación, presentada a seguir. 
Figura 3: Matriz de clasificación según las peculiaridades de los servicios.

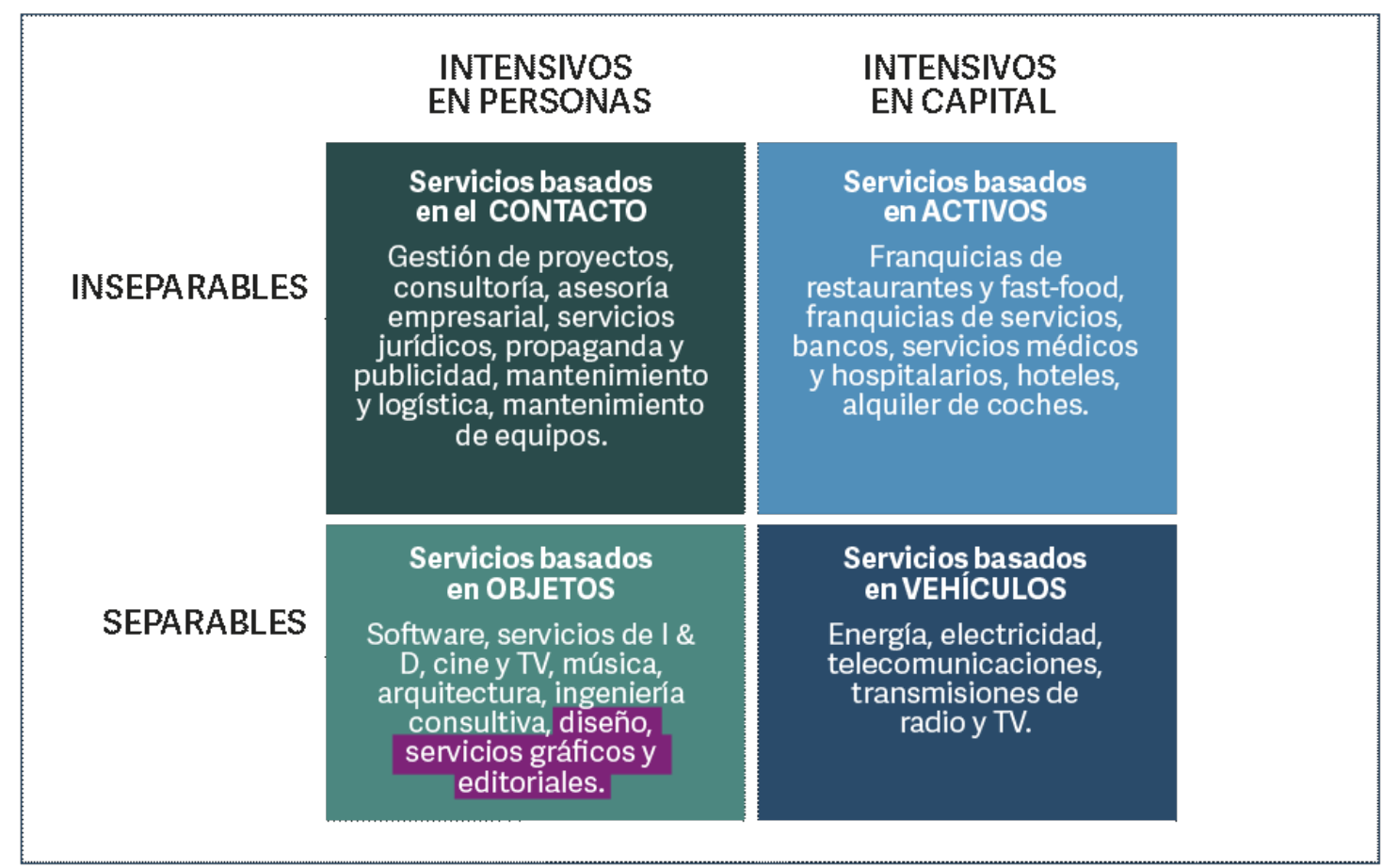

Fuente: Elaboración propia, datos tomados de: Rocha, A.; Mello, R.C; Silva, J.F. (2009). Internationalization patterns of Brazilian service firms. In: Ramsey, J.; Almeida, A. (2009) The rise of Brazilian multinational firms. Rio de Janeiro: Ed. Elsevier.

\subsection{Concepto y marco legal - exportación de servicios}

La exportación de servicios se encuentra definida en el Acuerdo General sobre Comercio de Servicios (AGCS, el GATS por sus siglas en inglés), que entró en vigor en enero de 1995 como resultado de la Ronda Uruguay ${ }^{16}$.

El acuerdo estableció los siguientes "modos de provisión" de servicios en la búsqueda de unificar criterios de clasificación.

- Comercio transfronterizo: el servicio mismo cruza la frontera.

Por ejemplo, un diseñador brasileño envía un e-mail con datos a un cliente en Argentina.

- Consumo en el exterior: el cliente viaja al país donde se provee el servicio. Por ejemplo, un turista brasilero de visita a Argentina durante sus vacaciones.

\footnotetext{
${ }^{16}$ Las exportaciones de servicios de América Latina y su integración en las cadenas globales de valor. Recuperado el 22 de Julio de 2018 de http://www.eclac.org/publicaciones/xml/3/35963/DocW37fin.pdf
} 
- Presencia comercial: el proveedor establece una presencia comercial en el exterior. Por ejemplo, un estudio de diseño brasilero abre una oficina sucursal en Argentina.

- Movimiento de personas físicas: el proveedor del servicio se mueve temporalmente al territorio de otro país para proveer el servicio. Por ejemplo, un diseñador brasilero viaja a Argentina por un mes para supervisar un proyecto de una exposición visual.

\subsection{Exportación de servicios en el mundo}

La contribución de los servicios a la economía ha aumentado a lo largo del tiempo. Entre 1980 y 2015, la participación de los servicios en el PBI aumentó en todos los grupos de ingresos, de 61 a $76 \%$ en las economías desarrolladas y del 42 al $55 \%$ en las economías en desarrollo. Los servicios son predominantes en todas las regiones en desarrollo, incluso en los países de menor grado relativo de desarrollo. El aumento de la producción de servicios en ese período corresponde en gran parte a un declive en la producción industrial de las economías desarrolladas y a la disminución de la producción agrícola en las economías en desarrollo. Los servicios también son predominantes en la generación de empleos. Se estima que en 2016 el sector de servicios fue responsable por casi la mitad $(49 \%)$ de los empleos globales. La importancia de los servicios es más acentuada en las economías desarrolladas (donde representa el $75 \%$ del total de empleos) que en las economías en desarrollo $(44 \%)^{17}$.

\footnotetext{
${ }^{17}$ Serviços 2016 - Panorama do Comércio Internacional. Recuperado el 22 de Julio de 2018 de http://www.mdic.gov.br/images/REPOSITORIO/scs/decin/Estat\%C3\%ADsticas_de_Com\%C3\%A9r cio_Exterior/2016/Panorama_Oficial_2016_Final_.pdf
} 
Figura 4: Evolución de la exportación de servicios en el mundo.

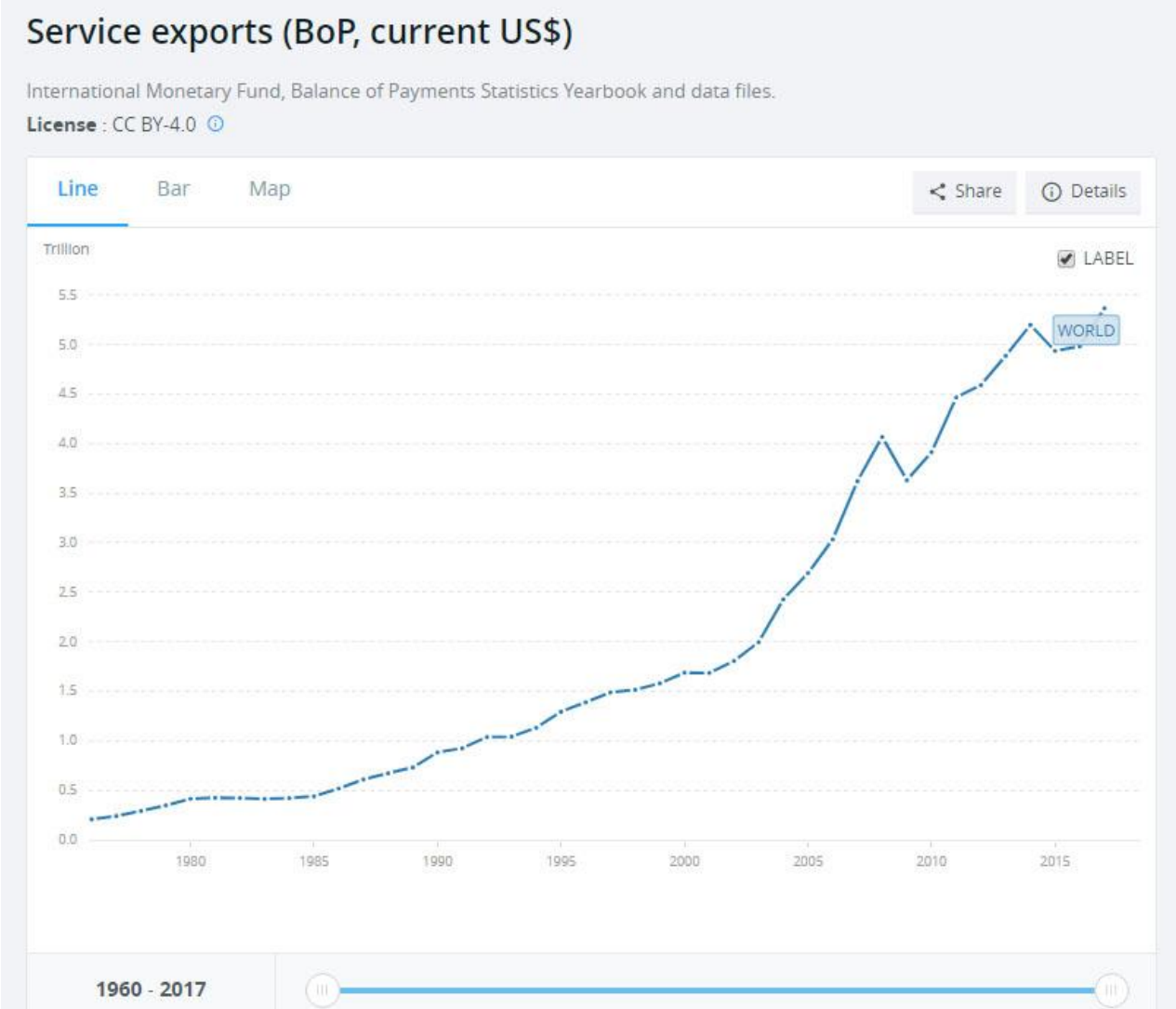

Fuente: https://data.worldbank.org/indicator/BX.GSR.NFSV.CD?view=chart

\subsection{Exportación de servicios desde países en desarrollo}

Desde mediados de los años noventa, las exportaciones de servicios de 20 países en desarrollo - incluyendo no sólo Brasil, India, la Federación Rusa y China, sino también Camboya, Ghana, Marruecos y Nigeria crecieron más del 15\% anual. De 1990 a 2007, antes de la crisis financiera mundial, el crecimiento medio de las exportaciones de servicios era del 8,7 por ciento para los países de alta renta, el 10,0 por ciento para los de bajos ingresos y el 13,0 por ciento para países de renta media-baja. La participación de los países en desarrollo en las exportaciones de servicios mundiales aumentó del $11 \%$ en 1990 al $21 \%$ en $2008^{18}$.

Los países en desarrollo están exportando no sólo servicios tradicionales, como

${ }^{18}$ Goswami, A. G., Mattoo, A., Saez S. (2012). Exporting Services: A Developing Country Perspective (Trade and Development). ( $1^{\mathrm{a}}$ ed) Washington: World Bank Publications. 
transporte y viajes (turismo), sino también servicios modernos, especialmente servicios 24 de alto valor, altamente especializados, como servicios digitales y servicios de información.

El éxito de algunos países en la exportación de servicios parece no estar relacionado con su desempeño en el comercio de bienes o su desarrollo industrial. De hecho, las exportaciones del sector de servicios de varios países en desarrollo están creciendo más que sus exportaciones de bienes y están contribuyendo a la diversificación de sus exportaciones. Algunos autores sugieren que está ocurriendo una "revolución de servicios".

El mercado global está en un punto de giro tecnológico. Nuevas tecnologías e innovaciones, ecosistemas industriales y el alcance en expansión de empresas de plataformas impulsadas digitalmente están alimentando el ritmo de una revolución en los servicios globales. Para garantizar el éxito continuo y la fuerza de exportación, las empresas necesitan reevaluar el futuro y adoptar modelos de negocio orientados a servicios. Aquellos con una visión osada pueden convertirse en los innovadores de mañana y liderar la revolución de los servicios. Al mismo tiempo, esto impone una serie de desafíos, como por ejemplo, atender a las demandas por talentos cualificados

Así que la "revolución de servicios" no es más que el crecimiento rápido de la renta, la creación de empleos, la igualdad de género y la reducción de la pobreza dirigida por servicios, y sería una alternativa para acompañar el crecimiento económico acelerado y aliviar la pobreza (Ghani 2010) ${ }^{19}$.

Es obvio el papel de la tecnología en el crecimiento del comercio de servicios. Los cambios tecnológicos están claramente reduciendo la necesidad de proximidad entre el productor y el consumidor. Estos cambios también están permitiendo la fragmentación de la producción en tareas que se pueden realizar en diferentes lugares. La fragmentación, que afecta a la producción de ambos: bienes y servicios, lo que significa que si antes, la producción sólo podría ocurrir en un solo lugar, ahora puede ser realizada en diferentes

\footnotetext{
${ }^{19}$ Goswami, A. G., Mattoo, A., Saez S. (2012). Exporting Services: A Developing Country
} Perspective (Trade and Development). ( $1^{\mathrm{a}}$ ed) Washington: World Bank Publications. 
regiones o incluso países. Los servicios de diseño y comunicación, logística, servicios 25 financieros, entre otros, permiten la conexión de tareas realizadas en diferentes lugares. ${ }^{20}$

Por ejemplo, un diseñador gráfico brasileño puede crear un proyecto de identidad visual para una obra de teatro que tendrá lugar en Argentina. Este proyecto de identidad visual incluye el logotipo de la obra, carteles, folletos y piezas de marketing digital para redes sociales. Los carteles y los folletos, por ejemplo, se pueden imprimir en una gráfica en Paraguay. La estrategia digital, que sería el post en redes sociales de las artes creadas para divulgar en Facebook, y los posts pagos y segmentados para un público específico, pueden ser hechos por una agencia de marketing digital en Uruguay. De esa forma descentralizada los países en desarrollo están aprovechando estas nuevas oportunidades para exportar servicios.

\subsection{Exportación de servicios en Brasil}

Considere comparaciones entre los quinquenios inicial y final del período 1995 a 2016. Según el Banco Central de Brasil ${ }^{21}$, en el quinquenio 1995-1999, la corriente anual promedio de comercio de servicios fue de 20.000 millones de dólares, lo que correspondió al 19\% de la corriente de comercio de bienes. En el quinquenio 2012-2016, la corriente ya era de US \$ 114 mil millones anuales, valor correspondiente al $28 \%$ de la corriente de bienes.

El aumento de la corriente de servicios fue más fuertemente influenciado por las importaciones, como muestra el gráfico abajo. De hecho, mientras que en el primer quinquenio las importaciones anuales promedio de servicios fueron de US \$14.500 millones, las exportaciones anuales promedio fueron de US \$ 5 mil millones. En el último quinquenio, la media anual de importaciones pasó a los 78 mil millones de dólares, mientras que la de exportaciones pasó a 37.000 millones de dólares. El gráfico muestra que una especie de "boca de cocodrilo" se abrió, llevando a un creciente déficit de la cuenta de servicios - en el primer quinquenio, el déficit anual medio fue de 8.400 millones de dólares, pero en el último quinquenio el déficit anual medio ya había subido a 40.000 millones de dólares.

\footnotetext{
${ }^{20}$ Guia Básico para a Exportação de Serviços - Versão Revisada - Julho 2017. Recuperado el 31 de julio de 2018 de http://www.mdic.gov.br/images/REPOSITORIO/scs/decin/Guia_B\%C3\%A1sico/Guia_B\%C3\%A1si co_-versao_2017.pdf

${ }^{21}$ Banco Central do Brasil. Recuperado el 22 de Julio de 2018 de https://www.bcb.gov.br/ptbr/\#!/home
} 
Figura 5: Evolución - Exportación e importación de servicios en Brasil de 1995 hasta 2016.

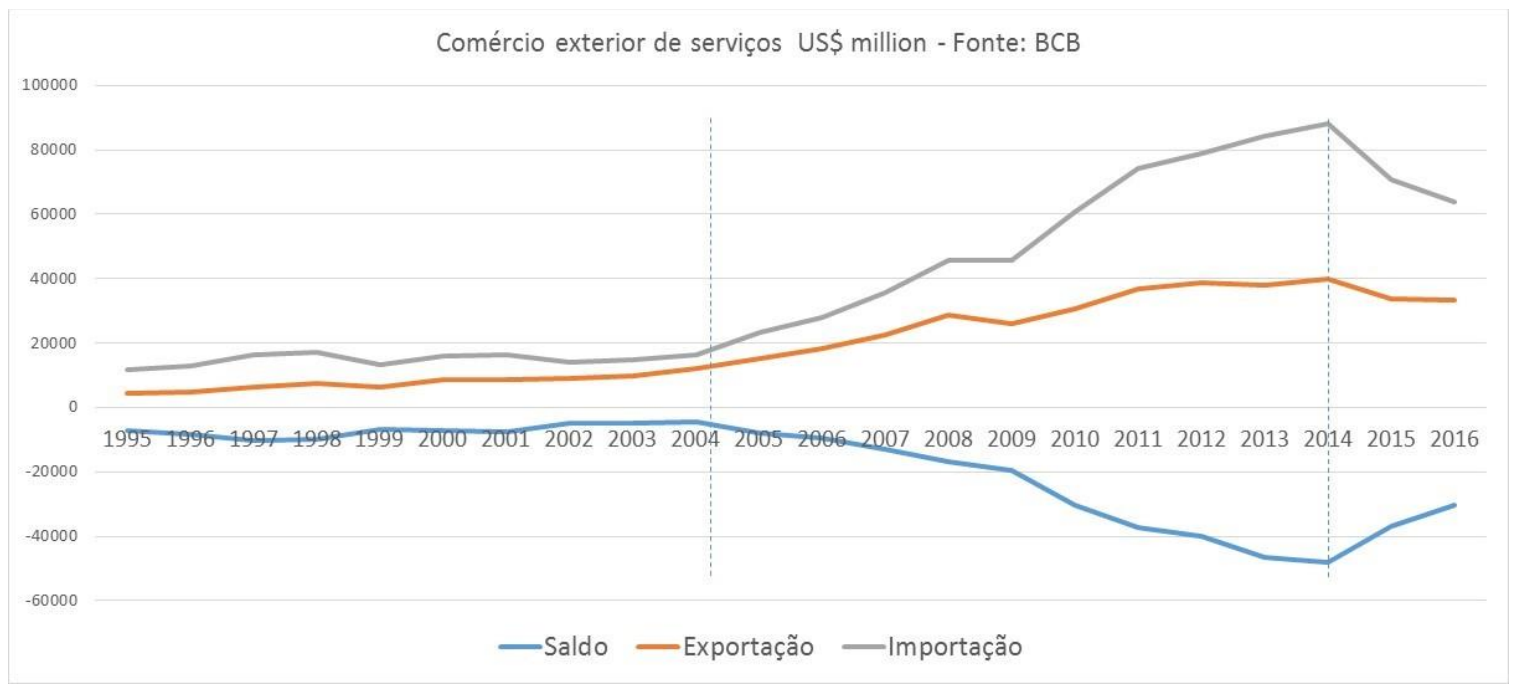

Fuente: Banco Central de Brasil. Recuperado el 31 de julio de 2018 de https://economiadeservicos.com/2017/05/30/comercio-exterior-de-servicos-o-que-vempela-frente/

El déficit del comercio de servicios pasó a tener creciente relevancia para el saldo de la balanza comercial agregada de bienes y servicios. En el primer quinquenio, el déficit anual medio de servicios correspondió al $61 \%$ del déficit de la balanza comercial. En el último quinquenio, el déficit anual pasó a corresponder a números situados en el intervalo entre el $100 \%$ y el $200 \%$ del déficit de la balanza comercial. Es decir, los servicios se convirtieron en el más importante determinante del saldo de la balanza comercial y causa fundamental del déficit de transacciones corrientes.

Como muestra el gráfico, parece haber habido cambios estructurales en el comercio de servicios a partir de 2004, cuando la corriente de comercio pasó a crecer rápidamente. A partir de 2014, sin embargo, la corriente de comercio entró en declive tirada principalmente por la caída de las importaciones.

La caída reciente de la corriente de servicios en Brasil puede ser explicada, al menos en parte, por la recesión y la devaluación del cambio. Pero es muy probable que una vez que la economía vuelva a recuperarse, las importaciones de servicios también vuelvan a recuperarse, pero a tasas desproporcionadamente mayores que la del crecimiento del PBI. Y esto se debe a la elevada elasticidad de la importación de servicios con relación al producto. El cuadro de recuperación también debe ir acompañado de un aumento del 
déficit de servicios porque la elasticidad de las importaciones es mayor que la de las exportaciones, lo que se debe, al menos en parte, de la creciente relevancia de los servicios en el comercio y en las cadenas globales de valor. ${ }^{22}$

\subsection{El futuro de las exportaciones de servicios en Brasil}

Es muy probable que la corriente de comercio de servicios siga aumentando en el futuro próximo y que influya cada vez más en el resultado de las cuentas externas. Además del diferencial de elasticidades, lo que determinará de hecho el aumento de la corriente de servicios será el explosivo crecimiento de la importancia de los servicios, de agregación de valor y diferenciación de productos (Industria 4.0) y de la economía digital en la producción y la gestión de la producción en el comercio y en el bienestar de las personas.

La gestión y el uso de datos, servicios en las nubes, e-commerce, entretenimiento digital, marcas, propiedad intelectual, diseño, marketing, distribución, uso de servicios de plataformas, entre muchos otros servicios sofisticados se están convirtiendo en componentes prácticamente obligatorios del día a día de las empresas y de los ítems de consumo de las personas. Como la mayor parte de esos servicios es, y si todo sigue como está, seguirá siendo importada, el déficit comercial de servicios probablemente aumentará sustancialmente en los próximos años.

Un indicador de esta tendencia son las cuentas externas de pagos de servicios de propiedad intelectual y de servicios de telecomunicación, computación e información. Las importaciones anuales promedio de propiedad intelectual pasaron de US \$1.000 a los 5.000 millones de dólares en el primer y último quinquenios, y las importaciones anuales promedio de servicios de telecomunicación, computación e información pasaron de US \$ 670 millones a US \$ 4 mil millones. En el último quinquenio, esas dos cuentas ya respondían, solas, por casi el $20 \%$ del déficit total de la cuenta de servicios ${ }^{23}$.

Estas tendencias, junto con la commoditización digital ${ }^{24}$, sugieren fuertemente que el comercio de servicios tiene que ser parte integrante de las políticas de crecimiento

\footnotetext{
22 Indústria, Comércio Exterior e Serviços - Estatísticas do Comércio Exterior de Serviços - 2016. Recuperado el 22 de julio de 2018 de: http://www.mdic.gov.br/index.php/comercioservicos/estatisticas-do-comercio-exterior-de-servicos/2555-estatisticas-do-comercio-exterior-deservicos-2016

${ }^{23}$ Comércio exterior de serviços - o que vem pela frente? Recuperado el 22 de Julio de 2018 de https://economiadeservicos.com/2017/05/30/comercio-exterior-de-servicos-o-que-vem-pela-frente/ ${ }^{24}$ What is digital commoditization? Recuperado el 28 de julio de 2018 de https://www.linkedin.com/pulse/what-digital-commoditization-jorge-arbache/?trk=v-
} 
económico sostenido, así como de las agendas de políticas comerciales, de inversión, 28 industrial, tecnológica, capital humano y de infraestructura. Al fin, ya hay suficientes pistas que demuestran que, en el futuro próximo, no será posible crear riquezas, generar empleos de calidad y entrar por la puerta de frente en las cadenas globales de valor sino a partir de la capacidad de desarrollar y gestionar servicios sofisticados ${ }^{25}$.

\subsection{Brasil quiere aumentar las exportaciones de servicios}

Brasil debe ampliar, en las próximas décadas, la participación del sector de servicios en la exportación. La evaluación es del secretario del Ministerio de la Industria, Comercio Exterior y Servicios (MDIC), Marcelo Maia. Según el último relevamiento del Banco Central, los servicios respondieron por el $1,91 \%$ de las exportaciones brasileñas y el $4 \%$ de las importaciones en $2015^{26}$.

El resultado es discrepante si se compara a la participación de los servicios en el mercado interno, en que el sector respondió por el $71 \%$ del Producto Bruto Interno (PBI) del país.

El Ministerio de la Industria, Comercio Exterior y Servicios estimula a empresas brasileñas de los sectores de arquitectura, diseño, audiovisual, juegos, publicidad y propaganda, ingeniería, comercio electrónico, entre otros. El objetivo es fomentar cada vez más el área que genera empleos más cualificados, además de agregar valor y sofisticación a los bienes agrícolas e industriales.

Según el secretario Marcelo Maia ${ }^{27}$, internamente, los servicios tienen un peso sustancial, de cerca del $70 \%$ del $\mathrm{PBI}$, pero estamos por debajo del potencial del país en el exterior.

Las estadísticas de Siscoserv ${ }^{28}$, sistema informatizado del MDIC (Secretaria de Comercio y Servicios), informan actualmente que los principales países para los que Brasil exporta

feed\&lipi=urn\%3Ali\%3Apage\%3Ad_flagship3_detail_base\%3BZ2IkPuArX\%2FACMS2Rbz\%2Ff9Q $\% 3 \mathrm{D} \% 3 \mathrm{D}$

${ }^{25}$ Guia Básico para a Exportação de Serviços - Versão Revisada - Julho 2017. Recuperado el 31 de julio de 2018 de

http://www.mdic.gov.br/images/REPOSITORIO/scs/decin/Guia_B\%C3\%A1sico/Guia_B\%C3\%A1si co_-versao_2017.pdf

${ }^{26}$ Brasil quer aumentar exportações de serviços. Recuperado el 22 de Julio de 2018 de http://www.brasil.gov.br/economia-e-emprego/2017/04/brasil-quer-aumentar-exportacoes-deservicos

${ }^{27}$ Brasil quer aumentar exportações de serviços. Recuperado el 22 de Julio de 2018 de http://www.brasil.gov.br/economia-e-emprego/2017/04/brasil-quer-aumentar-exportacoes-deservicos 
servicios son Estados Unidos, Holanda, Suiza, Alemania, Japón y el Reino Unido.

Estados Unidos, por ejemplo, utilizó servicios de relaciones públicas, comunicación y servicios profesionales y técnicos.

Según el presidente de la Asociación de Comercio Exterior de Brasil, José Augusto de Castro, exportar servicios significa exportar inteligencia, característica de países desarrollados. $^{29}$

El superintendente del área de comercio exterior del Banco Nacional del Desarrollo $(B N D E S)^{30}$, Leonardo Pereira Rodrigues, explica que la institución financia empresas de ingeniería de construcción, medicina, juegos e ingeniería consultiva y que hay potencial de evolución. Según el superintendente, las exportaciones en servicios son altamente calificadas y no tienen pérdidas.

\subsection{El Soft Power brasileño}

Soft power, o poder suave, es el término usado en la diplomacia para definir la competencia de un país para conseguir lo que desea por medio de su cultura y de su imagen. De sonrisas y paciencia en oposición a balas y cañones. El concepto fue delineado en los años 1990 por el científico político estadounidense Joseph Nye. No es algo concreto, no hay como medirlo en cifras, no se vende en la bolsa de valores, pero es innegable.

En Brasil, décadas de indignación y frustración con la corrupción alcanzaron su punto máximo en 2016, cuando una sucesión de escándalos dominó la política, y la presidente Dilma Rousseff fue cambiada, vía impeachment, por Michel Temer, que también es acusado de actos ilícitos. Con una situación tan crítica, Brasil se desplomó en el ranking internacional que mide el soft power, el " poder blando ", " poder suave " o " poder de convencimiento ", de acuerdo con el recién divulgado informe anual sobre el tema difundido por la consultora británica Portland.

\footnotetext{
${ }^{28}$ Secretaria de Comércio e Serviços - MDIC. Siscoserv - Sistema Integrado de Comércio Exterior de Serviços, Intangíveis e Outras Operações que Produzam Variações no Patrimônio. Recuperado el 22 de Julio de 2018 de http://www.siscoserv.mdic.gov.br

${ }^{29}$ Agência Brasil. Presidente da AEB reclama protagonisno do comércio exterior . Recuperado el 31 de julio de 2018 de: http://agenciabrasil.ebc.com.br/economia/noticia/2018-07/presidente-daaeb-reclama-protagonisno-do-comercio-exterior\#

${ }^{30}$ BNDES - O banco nacional do desenvolvimento. Recuperado el 22 de Julio de 2018 de https://www.bndes.gov.br/wps/portal/site/home
} 
Según el relevamiento de la consultora británica Portland, Brasil es ahora el $29^{\circ}$ colocado en el ranking, penúltimo de la lista de 30 países. La clasificación es seis colocaciones por debajo del $23^{\circ}$ lugar registrado en 2015, primer año del levantamiento, cuando la consultoría ya decía que Brasil estaba " en el límite del desastre político y económico ".

El sucesivo declive en el ranking Soft Power 30 sugiere que está llegando la hora de que Brasil deje de creer que su peso global y excelente reconocimiento de marca están garantizados, dice el estudio.

Según Portland ${ }^{31}$, Brasil se consolida aún más como un país decorativo, con buenos aspectos de ocio, pero con serios problemas.

Por más que Brasil siga siendo para muchos el país del sol, del fútbol, del samba y del carnaval, es importante que el gobierno tome acciones decisivas en su batalla contra la corrupción y reduzca los conocidos costos operacionales de hacer negocios en el país.

El ranking fue desarrollado por la consultora estratégica Portland y de investigación de "Place Branding", en sociedad con Facebook. Se calcula por la combinación de más de 70 bases de datos de diferentes fuentes sobre soft power, clasificados en siete categorías: Gobierno, Cultura, Educación, Participación Global, Emprendimiento, Digital, además de encuestas de opinión. Además, se entrevistaron once mil personas en 25 países para evaluar la interpretación sobre las diferentes naciones del ranking.

Pero incluso en un momento en que el país está manchado por los escándalos de corrupción, la violencia y la grave crisis económica, el apoyo a la selección en la copa de 2018 ayuda a llamar la atención sobre los aspectos positivos del país ${ }^{32}$.

La imagen de los brasileños como un pueblo mestizo, cordial y simpático y la tradición diplomática, a pesar de los problemas actuales, son puntos fuertes del soft power que contribuye a que otros países miren a los brasileños con más simpatía, especialmente por la forma "amigable" que el país se relaciona con sus pares.

\footnotetext{
${ }^{31}$ Welcome to the Soft Power 30. Recuperado el 22 de Julio de 2018 de https://softpower30.com/

${ }^{32}$ Por que tantos países torcem para o Brasil em Copa do Mundo. Recuperado el 22 de Julio de 2018 de https://exame.abril.com.br/mundo/por-que-ha-tantos-paises-torcendo-para-o-brasil-nacopa-do-mundo-da-russia/
} 
Los países europeos tienen que elegir un lado en la geopolítica, pero Brasil no. Y eso

contribuye a que el país no tenga enemigos y sea bien visto por países extranjeros. ${ }^{33}$

\subsection{Análisis FODA de Brasil como exportador de servicios}

Por último, se hace un análisis FODA de Brasil, analizando el país económicamente y evaluando el potencial del mismo como exportador de servicios, detectando así que factores pueden incidir positiva o negativamente en el desarrollo del plan de marketing internacional para la exportación de servicios de diseño gráfico.

Se buscan diferentes fuentes especializadas en el tema, para potenciar el perfil exportador del estudio de diseño gráfico del autor.

\section{Fortalezas}

- A pesar de los escándalos domésticos, la influencia de Brasil mundo afuera sigue fuerte (el poder del soft power brasileño).

- Optimismo de la sociedad - los brasileños creen en la recuperación de nuestra economía, en que las crisis son pasajeras y que demostramos competencia en salir de ellas.

- Empresarios emprendedores - tenemos un diferencial en el mundo que es la vivencia, experiencia y competencia de nuestro empresariado en todos los sectores que lucharon y luchan contra todas las adversidades del mercado y mala gestión pública, sobreviviendo a todas las crisis que ya pasamos, motivo de valorización por otros países a nuestro ambiente de negocios;

- Nuestras riquezas, tenemos tantas riquezas naturales y materiales, como humanas, lo que nos diferencia de todo el mundo y que nos da valor.

- Reconocimiento, empatía y valoración, a nivel mundial del perfil creativo y proactivo de los profesionales brasileños.

- Existencia de planes estratégicos del gobierno para la promoción de distintos sectores, incluso el sector de servicios y el sector creativo, como el PEIEX - Programa de Cualificación para Exportaciones. ${ }^{34}$

\footnotetext{
${ }^{33}$ Folha de São Paulo - Brasil perde soft power por frustrar expectativas, diz pesquisadora. Recuperado el 31 de julio de 2018 de: https://www1.folha.uol.com.br/mundo/2017/08/1912664brasil-perde-soft-power-por-frustrar-expectativas-diz-pesquisadora.shtml ${ }^{34}$ Programa de Qualificação para Exportação - PEIEX. Recuperado 31 de julio de 2018 de http://www.apexbrasil.com.br/qualifique-sua-empresa-peiex
} 
- Huso horario cercano respecto a otros países, principalmente con EE.UU., principal 32 país demandante de servicios.

- Importantes centros urbanos como São Paulo, Rio de Janeiro y Curitiba.

- Multiplicidad cultural y capacidad de adaptación a distintas culturas, y bajo algunos aspectos, afinidad cultural con mercados potenciales.

\section{Debilidades}

- Costo Brasil - encarece nuestros negocios sacando nuestra competitividad. Los impuestos son nuestro villano, toman alrededor del 35,7\% de nuestra producción y el código tributario es bastante complejo, conteniendo 92 tributos diferenciados y una tendencia a aumentar con la inclusión de la nueva CPMF (Contribución Provisional sobre Impulsión Financiera). Es más fácil aumentar tributos que reducir gastos y buscar productividad;

- Consumo exhausto - el gobierno adoptó la política de facilitar el crédito para la expansión del consumo. Vimos crecimiento de demandas en autos, televisiones, celulares, refrigeradores, heladeras, etc. Observamos el aumento del incumplimiento de prestaciones y la reducción drástica del consumo que nos señala un sesgo de caída para los próximos años;

- País exportador de commodities - exportamos productos de bajo valor agregado como mineral de hierro, jugo de naranja, carne y soja. Nuestro país es la gran economía más cerrada del hemisferio occidental, nuestro comercio representa sólo el $25 \%$ del PBI. EI precio de las materias primas sigue siendo bajo en el mercado internacional;

- Falta de mano de obra cualificada - empresas se enfrentan a serias dificultades para encontrar mano de obra cualificada y esa falta es una de las razones para los retrasos en algunos proyectos (construcción de obras, por ejemplo).

- La gestión económica empírica, los intentos de hacer crecer la economía depreciando la moneda con el fin de reducir los tipos de interés no dieron los resultados esperados, el PBI sigue siendo bajo y el crecimiento de la industria sigue siendo muy tímido.

- Las inversiones están en caída en el país. Brasil rebajado por Standard \& Poor's y podrá aún ser rebajada por otra agencia de riesgo, Fitch o Moody's, aunque el PBI del país en 2017 fue de 2,056 billones ${ }^{35}$;

\footnotetext{
${ }^{35}$ World Bank. Recuperado el 31 de julio de https://data. worldbank.org/indicator/NY.GDP.MKTP.CD?locations=BR
} 
- Las tasas de interés elevadas en función de variables económicas endógenas y exógenas;

- Inversiones en caída - debido a la situación macroeconómica de Brasil, el empresariado está con el pie en el freno, pues la incertidumbre es muy grande. Factor inhibidor.

- Estancamiento y recesión, cuadro que deteriora la economía brasileña, generando desempleo y caída de ingresos a todos los niveles, tanto privados como públicos, colaborando para aumentar la inflación;

- Tarifas, aumentos constantes de servicios correlativos al uso de agua y energía, además del aumento del combustible.

- Corrupción, hechos como "Mensalão" y Petrobrás (Operación “Lava-jato"), sacan la credibilidad de Brasil mundo afuera;

- Alto grado de informalidad del sector servicios en nuestro país.

\section{Amenazas}

- Competencia - el mercado está lleno de sorpresas tanto en proteccionismo mercadológico, como en proteccionismos económicos y financieros, perjudicando países; - Política proteccionista de los países del primer mundo;

- Mercado Chino - En teoría todos los productos representan una amenaza, algunos con tecnología otros con precios bajísimos, competencia desigual;

- Crisis Mundial - Afecta nuestro mercado de productos y financiero;

- La política económica de EE.UU. - El Banco Central de Estados Unidos debe aumentar la tasa de interés de Estados Unidos, como forma de atracción de inversiones externas, provocando futuras fugas de inversores en el país y aún corroborar para el aumento del valor del Dólar en el país aumentando la inflación;

- Mejores condiciones laborales para ciertos profesionales brasileños en el exterior, sumado al reciente escenario de crisis económica favorecen la fuga de capital humano.

\section{Oportunidades}

- Miembro de Grandes Organizaciones Comerciales y Políticas. Actualmente somos la 9a economía mundial ${ }^{36}$ y eso nos da poder;

\footnotetext{
${ }^{36}$ FMI, World Economic Outloook Database (abril de 2017). * Estimativa del FMI. International Trade Center (2017). Recuperado 22 de julio de 2018 de http://www.funag.gov.br/ipri/index.php/oipri/47-estatisticas/94-as-15-maiores-economias-do-mundo-em-pib-e-pib-ppp
} 
- Crédito de Carbono en abundancia ${ }^{37}$. Son certificados emitidos para una empresa o 34 un país que ha reducido su emisión de gases de efecto invernadero. Una tonelada de dióxido de carbono corresponde a un crédito de carbono. Este crédito puede ser negociado en el mercado internacional por países o industrias que no logran alcanzar las metas de reducciones de emisiones.

- Pre-Sal ${ }^{38}$. Área situado en aguas profundas, está compuesto por grandes acumulaciones de aceite de excelente calidad y con alto valor comercial. Puede nos hacer suficientes en combustible, posibilitando independencia y supremacía;

- Nuevas tecnologías de transmisión para, por ejemplo, las operaciones bancarias electrónicas.

- Envejecimiento de la estructura poblacional de los países desarrollados.

- Expectativa de crecimiento del comercio internacional de servicios en el comercio mundial;

- Además de la población de Sudamérica y España, tenemos más de 50 millones de población hispana en EE.UU., (uno de los países más demandantes de servicios) lengua que el autor domina con maestría ${ }^{39}$.

- Estratos poblacionales con alto poder adquisitivo en Centro y Sudamérica.

- Horizonte de la economía mundial 2020: análisis sectorial da cuenta de la necesidad de puestos con media y alta cualificación en servicios;

- Alto posicionamiento del sector publicidad y subcontratación de varias etapas de la producción de las piezas publicitarias: creación, diseño, ilustración, producción, distribución;

- Tipo de cambio favorable para la exportación;

- Fomento del uso del diseño y las industrias creativas vía asociaciones como la ABEDESIGN - Associação Brasileira de Empresas de Design ${ }^{40}$.

\subsection{Definiciones de diseño}

No es necesario ser un experto en marketing para acordar que, en general, lo que es "bello" vende más. Pero el hecho es que no todos comprenden la dimensión estética total

\footnotetext{
${ }^{37}$ Entenda como funciona o mercado de crédito de carbono. Recuperado 22 de julio de 2018 de http://www.brasil.gov.br/editoria/meio-ambiente/2012/04/entenda-como-funciona-o-mercado-decredito-de-carbono

${ }^{38}$ Petrobras - Pre Sal. Recuperado el 31 de julio de 2018 de: http://www.petrobras.com.br/pt/nossas-atividades/areas-de-atuacao/exploracao-e-producao-depetroleo-e-gas/pre-sal/

3915 datos (y un mapa) sobre el peso del español en EEUU que Donald Trump debería ver. Recuperado el 22 de julio de 2018 de https://www.lainformacion.com/mundo/Datos-espanolEstados-Unidos-Donald-Trump_0_992901230.html

${ }^{40}$ ABEDESIGN - Associação Brasileira de Empresas de Design. Recuperado el 22 de julio de 2018 de http://abedesign.org.br.
} 
donde el todo es mayor que la suma de las partes. Es decir, no se puede cambiar un detalle sin afectar el resultado final y su significado. Así que las personas se olvidan, o no saben que el bello no se opone a lo que es feo, el bello se opone a lo que es insignificante. $^{41}$

De esta forma, marcas, empresas y productos conquistan a las personas en la medida en que les significan algo, en una experiencia que es primordialmente estética (del griego Aisthetiké: Sensible).

Colocar una significación estética (o sensible) en las cosas, es una de las estrategias de un buen proyecto de diseño gráfico, algo que siempre ha encantado al autor como práctica profesional.

El diseño (design) en inglés tiene dos significados: como sustantivo, es el diseño del cual se puede construir algo. Como verbo, es planear, proyectar algo. Estos significados representan muy bien la práctica profesional del diseñador gráfico, mezcla de arte e ingeniería, intuición y método, imaginación y capacidad de realización. Comprender claramente cada problema, proponer soluciones dentro de una visión estratégica y buscar la perfecta ejecución de cada detalle es la mejor manera de proyectar, evitando modismos.

Según el AIGA ${ }^{42}$ - Instituto Americano de Artes Gráficas, organización profesional de diseño cuyos miembros practican todas las formas de diseño de comunicación, incluyendo diseño gráfico, tipografía, diseño de interacción, marca e identidad, el diseño gráfico es el arte y la práctica de planificar y diseñar ideas y experiencias con contenido visual y textual. El resultado final puede ser físico o virtual y puede incluir imágenes, palabras o gráficos. La experiencia puede ocurrir en un instante o por un largo período de tiempo. El trabajo puede ocurrir en prácticamente cualquier escala, desde la concepción de un único sello postal hasta un sistema nacional de señalización postal. Puede ser destinado a un pequeño número de personas, como un libro o exposición de edición única o limitada, o puede ser visto por millones, como el contenido digital y físico interconectado de una organización internacional de noticias. También puede ser para

\footnotetext{
${ }^{41}$ Junior, S.S. , Kawamura, K. (2001). Portfólio de Marcas. (1 ${ }^{\mathrm{a}}$. ed.) Curitiba: Ed. Lúmen Design.

${ }^{42}$ AIGA - The professional association for design. Recuperado 29 de julio de 2018 de https://www.aiga.org/
} 
El diseño que será experimentado en un instante es el más fácil de reconocer. Los diseñadores organizan el tipo, la forma y la imagen en carteles, anuncios, embalajes, y otros materiales impresos, así como información y gráficos para periódicos y revistas.

Los gráficos en movimiento son igualmente predeterminados y trabajados con la metodología proyectiva del diseño, pero deben ser experimentados a lo largo de un período de tiempo fijo, como los créditos de apertura de un film o un vídeo en línea que explica parte de un artículo de un periódico. Por lo general van más allá de lo visual para mover gráficos vectoriales, fotos y vídeo.

Muchos diseñadores también producen sistemas que se deben experimentar a lo largo del tiempo, pero no se limitan a la fabricación de objetos. Wayfinding ${ }^{43}$ es un conjunto de pistas constituidas por elementos visuales, auditivos, táctiles, entre otros, que permiten a las personas moverse dentro de un espacio de manera segura e informada.

Es una forma de gráficos ambientales, se refiere a marcas y señalización aplicadas en todo el edificio y en áreas externas, como parques, calles o carreteras. Mientras que cada signo o símbolo en el wayfinding es un trabajo de diseño, juntos forman un sistema más grande que ayuda a la gente a navegar mientras mantienen un sentido del carácter de donde están. El diseño del sistema - las relaciones entre todas estas partes - es donde el diseñador trae mayor valor.

Así como el wayfinding, el branding reúne todos los artefactos de una marca comercial o institucional, como una tarjeta de visita, una señalización, un logotipo o un anuncio, en un sistema visual. La forma en que se experimentan a lo largo del tiempo es el trabajo del diseñador gráfico. Ninguna parte se crea sin considerar las demás partes o sin planificar en cómo el cliente objetivo va a encontrar la marca por primera vez y luego desarrollar una relación con esa marca a lo largo del tiempo. En el siglo XX, un consumidor a menudo tenía sólo algunos puntos de contacto con una marca. Por ejemplo, si una persona volaba a algún lugar, vería expresiones de la compañía aérea en su billete, en la puerta, en el avión, en los uniformes de los comisarios de bordo y en varios artículos

\footnotetext{
${ }^{43}$ Case Study: WalkNYC Pedestrian Wayfinding. Recuperado 29 de julio de 2018 de https://www.aiga.org/aiga/content/why-design/aiga-case-studies/justified-2014/case-study-walknycpedestrian-wayfinding/
} 
impresos en el avión, como las mantas, servilletas o revistas de bordo. Quizás podría ver también un anuncio impreso o de televisión. Hoy en día, su experiencia todavía incluye todos estos elementos, pero ahora comienza bien antes de llegar al aeropuerto, cuando se compra el billete en el sitio web de la compañía aérea y recibe un correo electrónico de confirmación o ve un vídeo de seguridad y opciones interactivas a bordo. Después de llegar a su destino, también puede recibir un e-mail preguntando sobre la experiencia en el viaje o invitándole a interactuar con la marca de alguna manera (por ejemplo, dando su opinión, o incluso aprovechando algún tipo de descuento ofrecido por la compañía en una empresa asociada, como un restaurante o hotel). Según Khoi Vinh ${ }^{44}$, ex director de diseño del New York Times, esta expansión de los puntos de contacto se superpone a casi todos los medios y considera un período mucho más largo de compromiso con el cliente.

Los diseñadores también son responsables por proyectos interactivos en los que los contenidos se cambian a medida que se actualizan, así como las interfaces de pantalla que ayudan a las personas a navegar por mucha información. El diseño de interacción se diferencia de otros tipos de diseño, añadiendo otra consideración: responder a las acciones del visor o del usuario. El diseño editorial para web y móvil es el ejemplo más tangible, incluyendo sitios y aplicaciones móviles para publicación. Algunos proyectos digitales implican la presentación de información en streaming que cambian rápidamente, también conocidas como visualización de datos, creando interfaces interactivas y no interactivas.

Muchas empresas y los diseñadores que trabajan para ellas proyectan sus productos para que sean utilizados por un gran número de personas en todo el mundo, por lo que a menudo confían en estándares de diseño ampliamente aceptados y priorizan la usabilidad y la funcionalidad en detrimento de la expresión estética. Para proyectos grandes o complejos, diferentes diseñadores pueden trabajar en la interfaz de usuario (user interface o simplemente - UI), que se refiere al efecto y al diseño de lo que el usuario ve en el momento y la experiencia del usuario, y también en la experiencia total de los usuarios a lo largo del tiempo (user experience o simplemente - UX), a medida que se mueven a través de sitios web o aplicaciones móviles. ${ }^{45}$

\footnotetext{
${ }^{44}$ A Conversation with Khoi Vinh, Principal Designer, Adobe // Design Driven NYC. Recuperado 29 de julio de $2018 \mathrm{de} \mathrm{https://www.youtube.com/watch?v=u3D4HCq5Cac}$

${ }^{45}$ Krug, S. (2014). Don't Make Me Think, Revisited. A Common Sense Approach to Web Usability. ( $1^{\text {a }}$ ed) Indianapolis: Ed. New Riders.
} 
Así que, aunque el diseño gráfico no se establece como un campo donde es posible el 38 desarrollo de discursos más extensos, el alcance de su lenguaje en la formación del repertorio visual de las personas de todas las capas sociales es indiscutiblemente mayor que cualquier otro lenguaje en los días de hoy. ${ }^{46}$

En el caso del diseñador empresario, es evidente que tener su propia oficina requiere del profesional mucho más que talento proyectual. Hay impuestos, cuentas a pagar, plazos a cumplir, atención al cliente, prospección, estrategias de marketing y, hoy día, más que nunca, estrategias de marketing internacional.

Por estas razones, el autor admira, y toma como referencia a algunos colegas que están siempre con la agenda llena de trabajos para el exterior, como es el caso del diseñador gráfico brasileño Gustavo Piqueira, que está al frente de la Casa Rex ${ }^{47}$, empresa con sede en São Paulo que proyecta para varios países además de Brasil. Y también el diseñador gráfico argentino Adrián Pierini, que dirige la oficina multidisciplinaria Pierini Partners ${ }^{48}$, que básicamente desarrolla proyectos de diseño gráfico (branding, embalajes, editorial, consultoría creativa) para todo el mundo desde la ciudad de Buenos Aires.

\subsection{Percepciones del diseño gráfico brasileño y el diseño gráfico latinoamericano}

Según la revista británica Computer Arts $^{49}$, la escena del diseño en Brasil revela algo más que "fútbol y samba".

Si buscas una escena creativa llena de color, actitud e influencias multiculturales, no necesitas buscar más allá de Brasil. La multiculturalidad es una marca de Brasil también en el diseño. Algunos diseños, aunque hechos en Brasil tienen un gran sabor oriental, otros están inspirados en la literatura de Cordel, un lenguaje visual típico del nordeste brasileño. Aquí hay incluso diseño gráfico con influencia alemana.

Basándose en una paleta de colores tropicales para crear patrones ricos en mosaico para una robusta lista de clientes globales, incluyendo Nike, Coca-Cola y Absolut Vodka, el

\footnotetext{
${ }^{46}$ Piqueira, G. (2004). Morte aos Papagaios. (1 ${ }^{\mathrm{a}}$. ed.) São Paulo: Ed. Ateliê Editorial.

${ }^{47}$ Casa Rex. (2017). Recuperado el 15 de octubre de 2017 de http://http://www.casarex.com/

${ }^{48}$ Pierini Branding for the World. (2017). Recuperado el 15 de octubre de 2017 de http://www.pierinipartners.com/

${ }^{49}$ Brazil's design scene reveals more than just soccer and samba. Recuperado 18 de agosto de 2018 de https://www.creativebloq.com/computer-arts/brazils-design-scene-reveals-more-justsoccer-and-samba-61411957
} 
diseñador e ilustrador Guilherme Marconi ${ }^{50}$ cree que su estilo se hace eco del carácter 39 de su país natal: "Al igual que mi trabajo, Brasil es una gran mezcla de colores y razas, una ensalada de culturas y personas de los cuatro rincones del mundo ".

"A veces creo que podemos ser demasiado brillantes y coloridos", reflexiona el ilustrador autodidacta Kako ${ }^{51}$ desde su base en São Paulo. Kako a veces piensa y reflexiona si esto es realmente lo que somos, o simplemente lo que alguien quiere que seamos, pues Brasil tiene mucho que mostrar, y no siempre es tan brillante como parece.

Puede ser tentador encasillar un mosaico cultural de casi 200 millones de individuos con un cierto tipo de trabajo vibrante creativo levantado sobre rayos tropicales y ritmos de samba, pero según Kako, somos más profundos que eso. Brasil es un país enorme y muy difícil de definir. Desafortunadamente, somos estereotipados porque para otros es más fácil comprender el todo. Cuando es posible mostrar todas nuestras caras a la vez, queda claro lo difícil que es describir Brasil en el nivel creativo.

Dado que Kako es natural de São Paulo, ciudad que tiene la mayor población japonesa fuera de Japón, su propio trabajo tiene mucha profundidad e influencia de la cultura nipona. Él admite que le gustan sus ilustraciones más oscuras y sucias. Los trabajos hechos para la publicidad de Ford, Microsoft y el gigante sudamericano de bebidas AmBev rinden un buen dinero, pero él tiene más orgullo de su trabajo editorial más "atrevido" para la revista masculina Playboy.

"Creo que finalmente estamos llegando a tener una escena creativa bien definida", es la evaluación de Kako, respecto de la comunidad brasileña de diseño. Según él, aún no tenemos una escena como Europa, Japón o EE.UU. siempre tuvieron, pero tenemos mentes brillantes que nos inspiran a todos a alcanzar otro nivel.

Muchas personas talentosas se quedan en el país, principalmente en grandes centros urbanos como São Paulo o Rio de Janeiro, en lugar de ir a trabajar fuera de Brasil, y esa es la mejor manera de crear una poderosa escena creativa brasileña, concluye Kako. Según el diseñador, los grandes centros urbanos de Brasil son un gran entorno para

\footnotetext{
${ }^{50}$ Guilherme Marconi - Ilustrador. Recuperado 18 de agosto de 2018 de https://www.behance.net/marconi

${ }^{51}$ Kako Illustrator. Recuperado 18 de agosto de 2018 de http://www.kakofonia.com/
} 
trabajar, y la mayor demanda de nuevas ideas solo ayuda a los creativos a ser cada vez más creativos.

Kako no es el único que aprovecha al máximo los tonos más apagados. "Muchos de nosotros estamos trabajando con líneas, paletas de colores limitadas y una sensación general que es un poco más orgánica", revela Henrique Lima, del dúo de ilustradores Mulheres Barbadas 52 ("Mujeres Barbudas", en traducción). Un proyecto de Mulheres Barbadas para la marca brasileña Havaianas involucró no solo ilustrar un gran espacio de galería, sino también una gama de chanclas y zapatillas, todo en el estilo único del dúo. Según los creativos, la mayor ciudad de Brasil, São Paulo, es divertida y diversa, pero también fea y caótica, y eso es lo que ellos muestran en su trabajo creativo.

\subsection{La escena del diseño gráfico de Brasil de un vistazo}

\section{Centros creativos}

Con más de 17 millones de personas entre el centro cultural y de negocios São Paulo y la antigua capital del país, Río de Janeiro, las ciudades son imanes para el talento creativo establecido de Brasil, con la mayoría de las agencias de publicidad y estudios de diseño agrupados en São Paulo (apodado 'Sampa' por sus residentes). Pero también hay centros menores en todo el país, como Goiânia en el centro, Salvador en el norte y Curitiba en el sur.

Curitiba incluso es la ciudad natal del autor de la tesis, y es una ciudad reconocida internacionalmente como la capital verde del país ${ }^{53}$, debido a las grandes áreas de bosques y parques que la ciudad posee. También es reconocida como un gran centro urbano de innovación en variados campos creativos, como el urbanismo y su transporte colectivo, el BRT (Bus Rapid Transit) que ha incluso inspirado varias ciudades del mundo que adoptaron el sistema creado en la ciudad, que aquí cuenta con las conocidas estaciones "tubo" ${ }^{4}$. En el campo de las artes, la ciudad cuenta con el importante e

\footnotetext{
${ }^{52}$ Mulheres Barbadas. Recuperado 18 de agosto de 2018 de http://mulheresbarbadas.tumblr.com/ ${ }^{53}$ Story of cities \#37: how radical ideas turned Curitiba into Brazil's 'green capital'. Recuperado 18 de agosto de 2018 de https://www.theguardian.com/cities/2016/may/06/story-of-cities-37-mayorjaime-lerner-curitiba-brazil-green-capital-global-icon

${ }^{54}$ How Curitiba's BRT stations sparked a transport revolution - a history of cities in 50 buildings, day 43. Recuperado 18 de agosto de 2018 de https://www.theguardian.com/cities/2015/may/26/curitiba-brazil-brt-transport-revolution-historycities-50-buildings
} 
imponente museo Oscar Niemeyer ${ }^{55}$, que tiene formato de "ojo" y ya ha recibido importantes muestras de artistas internacionales, como Escher y Andy Warhol. Y por fin, en el campo del diseño, Curitiba ya ha recibido importantes eventos internacionales de diseño, como la "Semana D - Festival de Design", el "Design Week" y el "MADE Mercado, Arte, Design" que en 2017 aconteció por primer vez en la ciudad (el evento ya es tradición en São Paulo).

\section{Escuelas de diseño}

Hay varias escuelas de diseño prominentes en Brasil, incluyendo Senac, FAAP, FAUUSP, la Escuela Superior de Diseño Industrial (ESDI) y la sucursal brasileña del Instituto Europeo de Diseño (IED) ${ }^{56}$ Pero muchos creativos locales exitosos admiten que el curso superior fue solamente el comienzo, el primer "empujón" para aprender más, y así como el autor de la tesis, comparten la creencia de que la educación formal es importante pero no es el principal catalizador de la escena creativa.

\section{Eventos}

Un fuerte sentido de comunidad creativa ha llevado a eventos como el Bistecão llustrado (algo como el "Bistec llustrado", en traducción), una reunión mensual de diseñadores e ilustradores que comenzó en restaurantes de São Paulo y que desde entonces se ha extendido a otras ciudades. La revista digital y comunidad creativa IdeaFixa ${ }^{57}$ organiza varios cursos y reuniones, mientras que eventos anuales como el festival de diseño creativo Mercado Mundo Mix, que comenzó en 2013, también en São Paulo, incluyen talleres, proyecciones y exposiciones.

\section{El país}

Como el mayor país de Sudamérica, y el quinto más grande del mundo tanto por área como por población, aunque ha pasado por una fuerte crisis económica y política en años recientes, Brasil aún tiene una floreciente economía, colocándolo junto a China, India y Rusia (los conocidos como BRIC's ${ }^{58}$ ) como uno de los nuevos jugadores del diseño global. Su paisaje es tan diverso como su población, desde la selva tropical hasta

\footnotetext{
${ }^{55}$ Museu Oscar Niemeyer - Museum precariously perched on a massive yellow pillar. Recuperado 18 de agosto de 2018 de https://www.atlasobscura.com/places/museu-oscar-niemeyer

${ }^{56}$ Brazil's design scene reveals more than just soccer and samba. Recuperado 18 de agosto de 2018 de https://www.creativebloq.com/computer-arts/brazils-design-scene-reveals-more-justsoccer-and-samba-61411957

${ }^{57}$ Idea Fixa - Canal de inspiração e expressão. Recuperado 29 de agosto de 2018 de https://www.ideafixa.com

${ }^{58}$ BRICS 2018 - What is BRICS? Recuperado el 07 de septiembre de http://www.brics2018.org.za/what-brics
} 
regiones muy secas, yendo desde playas con palmeras a locales que presencian la ocurrencia de nieve en invierno, como es el caso en algunas ciudades serranas de los estados del sur durante los meses de invierno.

\subsection{Percepciones del diseño gráfico latinoamericano}

Según Felipe Taborda, autor del libro que compiló una serie de trabajos de diseñadores de toda América Latina: "Latin America Graphic Design"59, en América Latina el diseño gráfico comienza a desarrollarse como profesión a mediados del siglo XX, gracias al trabajo y al talento de diferentes personalidades del diseño. Estas personas ayudaron a forjar la comunicación visual como profesión, con la importancia y el carácter global que tiene hoy para la sociedad. En las décadas siguientes la profesión fue ganando una importancia aún mayor a partir de la instalación de las grandes agencias internacionales de publicidad en la región. Muchos de los grandes diseñadores gráficos contemporáneos incluso han dado sus primeros pasos en la profesión dentro de una agencia de publicidad.

A lo largo de su joven historia latinoamericana el diseño gráfico fue pasando por fases distintas siempre en concordancia con el vaivén social y económico de la región. Una región que nunca permanece quieta, ni social, ni política, ni económicamente hablando; y un lugar donde históricamente se enfrentaron y se mezclaron diferentes culturas. El diseño gráfico fue a menudo el encargado de funcionar como un espejo de la cultura y de lo que ocurría en la sociedad y hoy el diseño logró ocupar un lugar de protagonismo en la sociedad, siendo vital para el desarrollo cultural, económico y social. Según Taborda, una prueba de ese crecimiento es la gran cantidad de universidades en las que se ofrece el curso así como el número de eventos cuyo tema es el diseño.

El autor del libro que compiló una serie de trabajos de diseñadores de toda América Latina complementa diciendo que hacer esta selección lo hizo observar y reconocer que, a pesar de la cantidad de países que somos y que tenemos tantos y tan diferentes costumbres y folclores, no somos tan diferentes y ni tan distintos. El libro en cuestión muestra que por medio de la creatividad y el trabajo de los diferentes diseñadores (de los que ya están establecidos y son una referencia a los más jóvenes), todos somos latinoamericanos. Aunque tenemos cada uno su propia identidad y su propia historia, cuyos rasgos distintivos los diseñadores dejan transparentar en sus trabajos - como los

\footnotetext{
${ }^{59}$ Taborda, F., Wiedermann J. (2008). Latin America Graphic Design. (1 ${ }^{\mathrm{a}}$ ed) Cologne, Germany: Taschen.
} 
mexicanos con sus carteles y su burla de la muerte; los argentinos, con su tango y su

Maradona; o los brasileños, con su samba y sus colores, es posible ver que todos somos muy parecidos. En cada trabajo es posible percibir que hay una misma raíz y origen latinoamericano, dejando claro que también compartimos las mismas inquietudes, los mismos problemas, los mismos miedos e incluso las mismas energías para seguir adelante.

La llegada de los ordenadores determinó un nuevo estándar profesional a partir de finales de la década de los 80 . Así que lo que se ve hoy es una profusión de estudios y diseñadores gráficos en toda América Latina, que incorporaron a sus actividades otras áreas, como internet, video, ilustración y moda. Los medios digitales expandieron las fronteras de lo que antes se conocía como diseño gráfico. El profesional del siglo XXI está conectado a las diversas formas de comunicación y cruza permanentemente las fronteras de lo que antes definió la profesión. El constante crecimiento de acceso a la información generó un profesional aún más versátil, multimedia, cuya principal característica es la diversidad que lo rodea. América Latina presenta hoy una identidad cultural única en el mundo, incluso constituida de varios países con características individuales fuertes y distintas. La dinámica de su creatividad y cultura atestigua la vivacidad de la región. Sus productos, lenguas, música y pueblo forman uno de los principales y más ricos polos de identidad cultural en el mundo contemporáneo ${ }^{60}$.

\subsection{Experiencia personal}

Aunque seamos muy parecidos, como dijo Felipe Taborda más arriba, y que el autor está de acuerdo, en que cada país tiene su especificidad. Según experiencia del propio autor, cuando hizo un trabajo para EE.UU. y pudo hacer una breve entrevista, con respecto a lo que llevó a la elección de un diseñador brasileño para la creación de una identidad visual para una empresa estadounidense, lo que encanta en el perfil del diseño gráfico brasileño, es la dosis de alegría y color, lo que es un patrón "Latinoamérica" pero sin el tono de "drama" presente en el arte de otros países de América Latina, como es el caso de México.

\subsection{El diseño como disciplina exportable. Estudios de diseño que exportan}

En esta parte, vamos a analizar dos casos distintos de estudios de diseño latinoamericanos exportadores, una gran agencia brasileña que trabaja con grandes

\footnotetext{
60 Taborda, F., Wiedermann J. (2008). Latin America Graphic Design. (1 ${ }^{\mathrm{a}}$ ed) Cologne, Germany: Taschen.
} 
marcas, y un diseñador colombiano que prefiere trabajar solo (pero del mismo modo, 44 con proyectos para todo el mundo). Ambos casos son profesionales que ya trabajan con la exportación de servicios de diseño gráfico, tema foco de esta tesina. Se va a desarrollar brevemente sus perfiles y detectar características y metodologías comunes para aplicar al estudio del autor de la tesis.

\subsubsection{Estudio Colletivo de Diseño}

Colletivo ${ }^{61}$ es un estudio de diseño que ocupa un lugar especial en los corazones de varios creativos brasileños, principalmente porque sus trabajos de diseño, ilustración y motion design son muy inspiradores desde su fundación, en 2003. Ahora hay un montón de pequeños estudios que se espejan en ellos.

El estudio puede no ser conocido por el gran público, pero ciertamente ya se ha oído hablar o ya se ha visto algún trabajo de la empresa en los últimos años. Son de ellos las ilustraciones que dejaron más llamativas las campañas globales de la marca brasileña Havaianas en medios impresos y digitales en todo el mundo en el 2011. En Brasil, específicamente en la ciudad de São Paulo, hogar del estudio, son de ellos uno de los paneles que GE - pusieron en algunos edificios de São Paulo, en 2012 , rompiendo el vacío dejado por la retirada de los medios exteriores tras la Ley Ciudad Limpia, que pretendía disminuir la cantidad de publicidad en la ciudad, dejando apenas algunos lugares específicos para tal fin. ${ }^{62}$

El colectivo de diseñadores fue creado en 2003, pero surgió años antes, en las clases del curso de diseño gráfico de la Universidad Anhembi Morumbi, en São Paulo. Los bancos de la institución unieron Marcelo Roncatti, Fabio Couto, Vanessa Queiroz y David Bergamasco. "Éramos el grupo de nerds que llevaba los trabajos de la universidad en serio", afirma Roncatti. La dinámica bien aceitada en la universidad, sumada a la insatisfacción de cada uno de ellos con los primeros empleos, dio origen al Estudio Colletivo, empresa de diseño nacida muy enfocada en ilustración y que hoy, tiene hasta un brazo digital con atribuciones de agencia. "Al principio, hacíamos trabajos toscos y no teníamos prejuicio", dice Vanessa, socia y directora de atención al cliente, recordando los briefings para crear un sitio de velorio online y embalajes de productos eróticos.

\footnotetext{
${ }^{61}$ Estúdio Colletivo de Design. Recuperado 18 de agosto de 2018 de https://www.colletivo.com.br/ ${ }^{62}$ Meio \& Mensagem - O bem sucedido modelo do estúdio Colletivo. Recuperado el 31 de julio de 2018 de: http://www.meioemensagem.com.br/home/comunicacao/2012/12/19/o-bem-sucedidomodelo-do-estudio-colletivo.html
} 
La "gran virada" sucedió en 2005, cuando un antiguo sitio web especializado en cultura 45 brasileña - llamado Brazil Inspired - publicó algunos trabajos creativos del Colletivo y una corta entrevista con los socios. La visibilidad rindió los primeros trabajos de proyección internacional. El estudio pasó a ser contratado para trabajar con la agencia promocional TracyLocke, perteneciente al Omnicom, un gran conglomerado de publicidad de EE.UU.. Uno de los trabajos de mayor proyección para la agencia fue la serie de ilustraciones para tres envases de Pepsi Max para el mercado asiático en 2007. Otra ejecución internacional importante realizada en aquel año fueron viñetas de animación para el canal de televisión paga Comedy Central. Con eso ellos tomaron gusto por el área del motion graphics, o sea, la producción de viñetas y diseños con movimiento. La actuación en este frente permitió que el estudio pasase a cuidar de sitios de marcas de moda, mientras que comenzaron a comercializar en Internet (y en Facebook) carteles artísticos y también accesorios para celulares creados por sus diseñadores.

En paralelo, pasa a explorar la producción de contenido: es responsable, por ejemplo, por toda la estrategia de redes sociales para el lanzamiento de la película "Los Penetras". Otro trabajo de destaque del Colletivo fue la serie de ilustraciones - los "doodles" - del antiguo sitio web del banco brasileño Itaú. Según los socios, ellos tienen autonomía para ofrecer diferentes tipos de proyectos, y como la empresa existe desde 2003, es un buen indicativo de que valió la pena haber luchado en los tiempos de la universidad.

\subsubsection{Robinsson Cravents}

El autor de la tesis es amigo personal del diseñador gráfico colombiano Robinsson Cravents $^{63}$, que es especialista en la creación de identidades visuales, diseño de paquetes e ilustración 3D. Robinsson está ubicado en la zona rural a una hora de la ciudad de Medellín, segunda ciudad más grande de Colombia. Según el diseñador, allá él tiene la tranquilidad y el espacio para crear cosas notables para los ojos y las mentes.

Según Robinsson, el gran giro en su carrera se dio en 2010, cuando uno de sus trabajos fue destacado en Behance, una especie de red social y vitrina para creativos (diseñadores, ilustradores, fotógrafos, arquitectos). Missile Energy Drink ${ }^{64}$ fue una idea que él pensó y reflejó en unas pocas horas. La ejecución fue notable y continúa siendo. Según el diseñador, una idea simple al cepillarse los dientes causó un gran revuelo en

\footnotetext{
${ }^{63}$ Robinsson Cravents - Creative Director / Graphic Designer / Illustrator (2018). Recuperado 18 de agosto de 2018 de https://www.behance.net/robinssoncravents

${ }_{64}$ Missile - Energy Drink Identity. Recuperado 18 de agosto de 2018 de https://www.behance.net/gallery/280878/Missile-Energy-Drink-Identity
} 
Behance, red social estilo portfolio volcada a la creatividad, y le ayudó a obtener nuevos proyectos.

Muchos clientes y negocios han llegado gracias a Behance. De su estudio (según definición del propio diseñador: de un solo hombre), ha tenido la oportunidad de apoyar a muchos empresarios que comenzaron marcas en todo el mundo y la oportunidad de trabajar en algunos proyectos de diseño de branding y packaging verdaderamente excepcionales.

Desde 2010 hasta la fecha, ha creado diseños para más de 20 países (entre ellos EE.UU., Noruega y su país natal, Colombia). También recibió invitaciones de algunos lugares para celebrar conferencias o para apoyar proyectos universitarios.

Mucha gente piensa que Robinsson trabaja para grandes compañías, pero la verdad es que, diferentemente de las grandes agencias, él se siente más cómodo con nuevos proyectos.

Más libertad para crear y con buena suerte ver la creación crecer y convertirse en algo robusto. Al opuesto, las grandes empresas tienen parámetros muy definidos en términos de identidad y tratamiento. Los nuevos tienen todo para ser creado y es ahí donde él encuentra su placer.

Especializado en la creación de identidades visuales, para Robinsson un proyecto de identidad sólido, diferentemente de proyectos digitales que quedan vivos por menos tiempo, puede mantenerse en vigor durante décadas o al menos durante años. Por lo tanto, prefiere crear cosas que sigan vigentes por más tiempo, que se pueden imprimir y tocar.

\subsection{El perfil actual del Estudio de Diseño a nivel local}

Hoy el gran diferencial del estudio de diseño del autor, por tratarse de una PYME, es la atención personalizada al cliente, algo que está cada vez más valorado como se vio arriba con el surgimiento de la Industria 4.0.

Los proyectos de alta calidad, hecho comprobado por el interés (por el momento fortuito) por parte de clientes internacionales, y por el hecho de que algunos proyectos ya han sido galardonados o publicados en catálogos internacionales, también es un 
diferencial y fuerza que debe ser explotada al máximo. Es el caso de proyectos publicados en el blog de diseño internacional Design Ideas ${ }^{65}$, además de proyectos impresos en publicaciones, como es el caso del libro de creatividad e inspiración Brand Dropro: drops of creative solutions ${ }^{66}$.

El estudio ya ha diseñado para los EE.UU., Portugal, Paraguay, Uruguay, Bahrein, además de Argentina, ya que el autor es responsable de la creación de toda la identidad visual de ICEPEM ${ }^{67}$ institución educativa, que tiene una fuerte presencia en Argentina ofreciendo programas especiales de maestría y de doctorado para brasileños, modo por el cual incluso el autor conoció e ingresó en el presente curso de Maestría en Marketing Internacional de la UNLP.

Otro diferencial del estudio es el conocimiento en marketing del autor, adquirido en vivencias profesionales a lo largo de la carrera, trabajando directa o indirectamente con departamentos de marketing de diferentes empresas, además de la presente maestría.

Este conocimiento en marketing hace que el proceso proyectual tenga un direccionamiento bastante objetivo y estratégico, buscando siempre el aumento de facturación de las empresas clientes del estudio.

La consultoría creativa también puede ser considerada otro diferencial, pues muchas veces los clientes buscan por los servicios creativos de diseño gráfico con el objetivo de diferenciarse en el mercado, pero sin saber con seguridad cómo o en qué soportes hacer tangible esa diferenciación, o incluso con ideas equivocadas acerca de la visual o divulgación de su producto.

Como la mejor arma del diseñador gráfico es su repertorio, el autor siempre buscó leer mucho e investigar respecto de distintos, pero convenientes temas. Por ejemplo, al hacer un proyecto para una empresa productora de frutas, tuvo que hacer una profunda pesquisa/investigación respecto del tema para crear el concepto visual de la empresa.

\footnotetext{
${ }^{65}$ Agreste - Recuperado el 23 de Agosto de 2018 de https://www.designideas.pics/agreste/

${ }^{66}$ Brand Dropro: drops of creative solutions - Recuperado el 23 de Agosto de 2018 de https://www.amazon.com/s/field-keywords=9781388585860

67 Icepem - Instituto de Consultoria e Elaboração de Projetos Educacionais do Mercosul Recuperado el 23 de Agosto de 2018 de: http://icepem.com.br
} 
También es válido comentar que al autor siempre le interesaron las culturas

extranjeras, lo que en cierto modo significa estar en contacto con una visión del mundo diferenciada, práctica que viene a agregar al personal y al profesional. Pues la mejor arma del diseñador gráfico es su repertorio visual. Y no tiene mejor forma de aumentar el repertorio visual que estar viviendo en este mundo globalizado. Es decir, estar constantemente en estado activo de curiosidad, viendo las cosas de otra manera, hablando con otras personas, conociendo otras lenguas, resignificando algunos valores, y por ende, ampliando los propios horizontes.

El estudio hoy trabaja con el desarrollo de: identidad visual, embalaje, editorial, catálogos y piezas gráficas, ilustración, ambientación / señalización y diseño digital.

Estos tipos de proyectos, ya se han desarrollado para los más variados tipos de clientes: teatros, editoriales, sindicatos profesionales, empresa de frutas, consultorías, escuelas de negocios, constructoras, alimentación, artes y eventos.

La metodología de trabajo del estudio es la siguiente:

En un primer momento se hace una breve entrevista con el cliente vía briefing (ver anexo I), para aclarar algunas cuestiones: definir qué es el negocio, y cuáles son los objetivos del mismo, definir qué tipo de proyecto será desarrollado, cuál es la estrategia y cuál será el concepto y línea gráfica a seguir con el fin de mejorar el rendimiento del negocio.

Definido qué proyectos serán desarrollados, se envía una propuesta de presupuesto y contrato (ver ejemplo, anexo II) que una vez aprobado, se acuerdan los plazos de entrega.

En el transcurso del proyecto, se envían noticias semanales al cliente para no perder el contacto y mantener viva la comunicación e ideas principales del proyecto.

En el caso de proyectos más largos, se puede combinar la entrega de proyectos en etapas. Por ejemplo, una empresa que ha contratado el desarrollo de su identidad visual y su sitio web, en un primer momento se puede arreglar la entrega de la identidad visual. En una segunda etapa, definida para algunos días después de la entrega de la identidad, se entrega el sitio web. 
Con la entrega de los materiales, una llamada telefónica es hecha para que el cliente 49 certifique la satisfacción por los servicios prestados. Esto es una buena práctica de CRM (Customer Relationship Management) o sea: administración basada en la relación con los clientes, también conocido como marketing relacional. Ya que es una tendencia que el modelo de gestión de las organizaciones sea cada vez más basado en la satisfacción del cliente.

Normalmente los proyectos son divulgados en redes sociales y casualmente en algún blog o publicación especializada, con el propósito de crear una divulgación de ambos (cliente y estudio de diseño) de manera orgánica. Esta práctica, prestigia al cliente y crea valor y conocimiento para el proyecto y para el estudio de diseño, lo que es bastante importante. Pues ya dice el dicho popular: "Quien no es visto no es recordado."

El estudio hoy cuenta con una estructura pequeña, con apenas 2 empleados, además de una red de contactos interdisciplinaria de disciplinas complementarias, como la fotografía, TI y programación, arquitectura, decoración de interiores y consultores de marketing.

Esta red de contactos local, que incluye desde amigos y conocidos del autor, hasta antiguos clientes, que con solicitudes de trabajos recurrentes o indicaciones han garantizado un flujo constante de proyectos para el estudio.

\subsection{Conclusiones}

Las particularidades aquí detalladas, positivas o negativas, son muy importantes para la elaboración de un plan de marketing internacional para la exportación de servicios de diseño gráfico. Este debe ser capaz de influir claramente en las decisiones estratégicas y ser implantado en el mix de marketing. Debe tener en cuenta las diferencias y los puntos en común con el comercio de mercancías, además de las tendencias más actuales del mercado de manera general, como la industria 4.0 y la estrategia de lean startup, lo que nos permitirá planificar un plan de marketing exitoso a largo plazo.

Como a menudo los servicios necesitan ser adaptados a las necesidades específicas de los clientes, esas adaptaciones se deben hacer con la colaboración y la participación de ellos, tendencia cada vez más observada en el mercado, de manera general, con la Cuarta Revolución Industrial. Esta implicación del cliente requiere que el exportador del servicio disponga de habilidades interpersonales y sensibilidad cultural aún más altas de las exigidas por un exportador de productos manufacturado. 
También podemos ver la situación actual de la exportación de servicios en Brasil de manera positiva: incentivada por el gobierno, emergente y con gran potencial; y del lado opuesto: dosis de incertidumbre y falta de información. Por lo tanto, el estudio del autor, al iniciarse como empresa exportadora, debe estar profundamente enfocado en los requisitos necesarios para posicionarse como exportador a medio y largo plazo: definir claramente qué servicios va a exportar, conocer su mercado objetivo, generar intercambios y contacto con las agencias de fomento, fortalecer los puntos fuertes de su sector y profundizar la red de contactos.

Potenciar las oportunidades y estar preparado para capturar el amplio crecimiento que el sector experimentará, requerirá no sólo recursos humanos calificados e infraestructura de calidad, sino también la contribución innovadora y creativa del perfil de la empresa para destacarse de la competencia. El énfasis en los puntos fuertes del perfil exportador brasileño debe enfocar el proyecto en cuestión, en la reputación de los profesionales y de la fuerza de trabajo, con claras ventajas del sector creativo que sigue demandando aún más trabajo a raíz de revoluciones recientes en el mercado.

La oportunidad del estudio en dar continuidad a sus primeros pasos en el comercio internacional de servicios le genera beneficios para trascender el mercado local, y encima, posicionarse en el mismo con una imagen global que repercutirá en su calidad y valor de proyectos. También se podrá mejorar sus procesos de trabajo, haciéndolos más eficientes y competitivos.

El hecho, es que, realizar proyectos para fuera de su país, es naturalmente un indicador de excelencia, pues la empresa o el profesional deben tener un padrón de calidad de nivel global para atender a los demandantes de cualquier parte del mundo.

También es válido comentar que al autor siempre le interesó las culturas extranjeras, lo que en cierto modo significa estar en contacto con una visión del mundo diferenciada, práctica que viene a agregar al personal y al profesional. Pues el mejor arma del diseñador gráfico es su repertorio visual. $Y$ no tiene mejor forma de aumentar el repertorio visual que estar viviendo en este mundo globalizado. Es decir, estar constantemente en estado activo de curiosidad, viendo las cosas de otra manera, hablando con otras personas, conociendo otras lenguas, resignificando algunos valores, y así, ampliar sus propios horizontes. 
En referencia al mercado de destino podemos recomendar que inicialmente el estudio 51 del autor ${ }^{68}$ inicie su experiencia exportadora en EE.UU., país con gran demanda creativa y que ya ha demandado los trabajos del estudio de manera fortuita. Se tomará como referencia a otros colegas de profesión que ya exportan sus proyectos de diseño gráfico y se aprovechará de todos los puntos fuertes de Brasil como un país visto con muchos puntos positivos desde la mirada internacional.

También podemos visualizar un panorama muy positivo sobre el diseño gráfico brasileño y latinoamericano y la importancia y valoración cada vez mayor que la profesión asume en el actual ambiente de negocios.

Es importante reafirmar que la asociación constante promovida en diferentes sectores, como el académico, los medios corporativos, creativos e institucional, crea una red de contactos fuertes, ayudando a la empresa a posicionarse como un actor en el mercado y estar actualizada sobre el know-how para exportar servicios de diseño gráfico.

El estudio del autor tiene un perfil de calidad ya reconocido incluso internacionalmente, además de poseer conocimientos complementarios como el marketing y vivencias en culturas extranjeras, hechos que deben ser aprovechados al máximo en el plan de marketing internacional.

No debemos dejar de lado la tarea de promover una construcción continua y profunda de una identidad de diseño latinoamericana que nos permita posicionarnos a largo plazo como una alternativa concreta al mundo. El estudio tiene un perfil competitivo que debe ser traducido en el plan de marketing para penetrar en el mercado internacional de manera coherente, estable y continuada.

\footnotetext{
68 Érico Almeida - Graphic Designer. Recuperado 29 de julio de 2018 de
} http://www.ericoalmeida.com 


\section{CAPÍTULO 3: Programas de acción necesarios para la exportación de servicios} de diseño gráfico.

La propuesta de esta tesis es demostrar que una pequeña empresa, como el estudio del autor, puede exportar servicios de diseño gráfico a medio y largo plazo, basado en un plan de marketing internacional estratégico que pretende captar un nicho de mercado inicial en EE.UU., un mercado de gran demanda por servicios creativos, y con gran presencia de latinoamericanos, para dar continuidad a algunas experiencias internacionales fortuitas ya vivenciadas por la empresa con ese país.

Así, en este capítulo, vamos a desarrollar el plan de marketing internacional que tiene como objetivo principal que la empresa alcance de hecho la internacionalización, con el objetivo de estructurar a largo plazo una unidad de negocio operacional inclusiva y complementaria dentro de la estructura actual.

\subsection{Perfil de empresa, misión y visión}

Actualmente el estudio del autor posee reducida experiencia internacional, con casos aislados de clientes de otros países que demandaron servicios de manera fortuita, al conocer la empresa vía internet o vía algún contacto personal del autor.

En concreto, el primer trabajo internacional fue para la empresa ICEPEM, cuando en 2009 se definió, en principio, la marca y todo el patrón gráfico de la empresa especializada en ofrecer programas de educación superior de universidades argentinas para brasileños. En esa misma época, también definimos el proyecto gráfico y diagramamos algunas ediciones de una antigua revista de negocios que circulaba en Paraguay. Posteriormente, con los contactos y la presencia digital del estudio con la publicación de la primera versión del sitio web/portfolio digital con la selección de algunos trabajos desarrollados, nuevos proyectos internacionales comenzaron a surgir. Desarrollamos catálogos y piezas promocionales para un evento del Instituto de Vinhos do Douro e Porto, un grupo portugués de productores de vino que hizo un evento en la ciudad de Curitiba, dónde se ubica el estudio. También desarrollamos una marca y algunos materiales gráficos para una agencia de comunicación ubicada en Bahrein, en los Emiratos Árabes Unidos, y algunas piezas gráficas para Electrolux de Uruguay, por vía de una agencia de marketing local. 
El estudio también ya fue buscado por clientes de Canadá, Chile y Alemania, pero en proyectos que no se pudieron concluir por diferentes razones.

El objetivo del presente plan de marketing internacional es estar en contacto con clientes internacionales de manera recurrente y generar ganancias expresivas, o sea, buscar de hecho la internacionalización de la empresa.

La Misión del estudio hoy es: Inspirar momentos de optimismo, felicidad y diversión, creando valor y haciendo la diferencia en el mundo, con diseño creativo y de calidad que atienda a los objetivos del cliente.

Visión: Creemos en el diseño como herramienta interdisciplinaria para promover la innovación, traer conocimiento y nuevas formas de pensar y actuar. El diseño debe ser una herramienta de transformación socio ambiental y económica.

\section{Nuestros Valores son:}

Creatividad, innovación, colaboración, interdisciplinariedad, ética, integridad, calidad, diversión y emprendimiento.

La estrategia de internacionalización del estudio está alineada con su visión, enfocada en una visión interdisciplinaria del mundo y en generar vínculos e intercambios con empresas de otros países, ofreciendo servicios con alto nivel de calidad a nivel global.

En el nivel de capacidad instalada, el estudio cuenta con 3 máquinas de la marca Apple, banda ancha de internet de 10 megabytes, wetransfer y herramientas como whatsapp para negocios, Skype, teléfonos celulares y de línea para generar un contacto fluido con el exterior. Su equipo de trabajo está formado por especialistas en diferentes áreas del diseño, más específicamente: branding, diseño digital e ilustración.

Los profesionales del estudio están pasando actualmente por varios entrenamientos para manejar también la parte de motion design, a través de cursos de softwares específicos del área como el After Effects, software propio para la creación de vídeos y viñetas, y el Cinema4D, que es un software propio para hacer ilustraciones en $3 \mathrm{D}$, y que también crea animaciones. Esto es para estar actualizado con las últimas prácticas y tendencias del mercado creativo, mejorar las presentaciones de los proyectos, crear ilustraciones más 
realistas e interesantes, además de abrir un nuevo campo de actuación para el estudio 54 muy pronto, el motion design.

El estudio presenta un alto nivel de compromiso con el desarrollo del presente objetivo del plan de marketing, buscando perfeccionar la filosofía de la empresa: acompañar y apoyar a las empresas en sus procesos de desarrollo y crecimiento, dando un aspecto comercial, innovador y diferenciado al enfoque de diseño y comunicación. El estilo de gestión de la empresa se caracteriza por ser horizontal y de intercambio. Todos los integrantes de la empresa tienen una actuación holística e interdisciplinaria, con visión macro e interrelacionada.

El sector de diseño, según lo desarrollado en el capítulo anterior, no está totalmente posicionado como un servicio exportable, como acontece hoy con los servicios de transporte, sino que forma parte de un conjunto de disciplinas y profesiones creativas que están explotando sus habilidades y talentos.

También detectamos una etapa recurrente y continuada en que las pequeñas y medianas empresas siguen asumiendo cada vez más que el diseño es un servicio que mejora el rendimiento de los negocios. Esta creencia es fundamental y debe ser promovida tanto en el discurso externo como en el interno, ya que el estudio sostiene con absoluta seguridad que sus servicios son capaces de impactar totalmente en la realidad y el futuro financiero de las empresas.

\subsection{Objetivo general y objetivos específicos del Plan de Marketing}

El principal objetivo del plan de marketing a desarrollarse es que el estudio del autor trascienda el mercado doméstico en la primera etapa, estimada para durar cerca de 12 meses, con la obtención de 2 a 3 unidades de clientes con características similares en Estados Unidos.

En la próxima etapa, compuesta por un período de 6 a 12 meses, el objetivo es generar un carácter estructurado de continuidad en las exportaciones que significan la internacionalización de los servicios ofrecidos, que corresponda a un $50 \%$ de las ventas totales del estudio con una cartera de clientes activos.

Como objetivos específicos y secundarios, se busca el aumento de la rentabilidad de la empresa, obteniendo mayor status y prestigio con las exportaciones realizadas, además de elevar la empresa al status de liderazgo local, generando una imagen fuerte de la 
marca con una estrategia para expansión de negocios con calidad internacional. Se considera también relevante el refinamiento del know-how diario, afinando los procesos de proyecto con la experiencia y vivencias adquiridas.

A largo plazo, se espera que la internacionalización de servicios funcione como una unidad de negocios complementaria del mercado local, y que con ello la empresa pase a ser vista y recordada como de nivel de calidad internacional. Se utilizará la misma estructura operativa, compartiendo recursos humanos que deberán ser cada vez más entrenados para ello. Por lo tanto será importante entrenar y reclutar colaboradores que tengan interés en diferentes culturas, sepan inglés $y$, obviamente, cuando se trata de una empresa latinoamericana, también la lengua española.

\subsection{Estrategia del Plan de Marketing}

En cuanto a la estrategia de mercado, se aplicará un criterio de segmentación y concentración, que se refiere a la concentración de esfuerzos y recursos en un número reducido (EE.UU.) y segmentado de mercados (PYMES), alcanzando un know-how que permite una relación a largo plazo.

La estrategia inicial será penetrar desde el perfil del estudio, que es destacado por un estilo de gestión confiable, accesible y amistoso, donde las decisiones se toman en conjunto con los clientes. Generando sinergia entre el conocimiento de diseño, comunicación y marketing, además de entrenamientos constantes, el estudio es una empresa que entra lista en el nuevo paradigma VUCA ${ }^{69}$. Esta palabra se utiliza con mucha frecuencia en el ambiente de management, mentoring y counselling, y está afectando cada vez más el trabajo del diseñador. Es la sigla en inglés que corresponde a: Volatility, Uncertainty, Complexity y Ambiguity (Volatilidad, Incertidumbre, Complejidad y Ambigüedad). Hoy día, las prioridades y las cosas a las que debemos prestar atención en nuestro trabajo cambian muy rápidamente. Esto implica dirigir nuestras acciones diarias con enfoque en la flexibilidad. O sea, estar abierto al nuevo y al cambio, hacer autoevaluaciones y entrenamientos constantes, y prestar especial atención en la cultura organizacional interna.

En cuanto a los servicios definidos para ofrecer: identidad visual, embalaje, editorial, catálogos y piezas gráficas, ilustración, ambientación / señalización y diseño digital, la

\footnotetext{
${ }^{69}$ Harvard Business Review - What VUCA Really Means for You. Recuperado 01 de septiembre de 2018 de https://hbr.org/2014/01/what-vuca-really-means-for-you
} 
idea es posicionar el estudio como una referencia brasileña en el mercado

internacional, identificada y reconocida por la creación de proyectos visuales de altísimo nivel.

La principal ventaja competitiva proporcionada por el Estudio es la consultoría creativa aliada a los conocimientos prácticos de marketing. Esto se incluye en cada servicio ofrecido y se aplica en todo el proceso de definición del proyecto en cuestión. Por ejemplo, el estudio a través de escucha atenta e interpretación de lo que el cliente dice, puede evaluar si el cliente realmente necesita un nuevo sitio web, o si necesita simplemente de una campaña de marketing digital para conocer el sitio web ya existente (y obviamente, la empresa). La necesidad del cliente se aborda para descubrir la necesidad real. No hay piezas gráficas o estéticas aisladas, sino comunicación integral y estratégica que contribuye a la imagen y competitividad de la empresa.

Es importante también destacar la experiencia que tenemos en situaciones de crisis, es decir, enfatizar el perfil nacional, de que empresas brasileñas se destacan como habiendo pasado por variadas crisis económicas, emergiendo más fuerte o encontrando nuevas formas de articulación (cambiando la estrategia, foco o foco y función). Pues ya es sabido que los tiempos de crisis son los principales disparadores de la creatividad. Esta característica puede ser utilizada como una fortaleza para posicionar el estudio en su proceso de internacionalización.

La estrategia se cierra con enfoque al tipo de empresa que es atendida: PYMES de EE.UU. que no logran acceder a los grandes estudios caros, segmento que suele recibir poca atención y representa una gran oportunidad de negocio. Dar respuesta y apoyo a estas empresas en crecimiento en un segmento relegado por grandes estudios de diseño y agencias de publicidad que tienden a apuntar a las grandes empresas y multinacionales.

\subsection{Segmentación y mercado meta}

En cuanto a la selección de mercados, vamos a enfocar en un país que tiene gran necesidad de servicios de diseño, una gran población latinoamericana, y de acuerdo con experiencias anteriores del propio autor, es bien receptivo al perfil creativo y multidisciplinario brasileño.

El mercado objetivo será las PYMES de EE.UU. que buscan tener una imagen global y que necesitan invertir en el posicionamiento de su marca o producto. Hoy, las PYMES de 
EE.UU. se consideran agentes potenciales de cambios globales. Interpretar sus necesidades actuales para alcanzarlas y ser capaces de responder a través de diseño y comunicación, dándoles visibilidad a través de una imagen de calidad diferenciada y sostenible a lo largo del tiempo.

En el primer caso, un aspecto existente será promovido en el momento del desarrollo del presente plan, el desarrollo de un proyecto en la ciudad de Austin, Texas, Estados Unidos.

Se ha comprobado que las empresas del país en cuestión que hoy quieren actualizar su imagen y dar relevancia al diseño e identidad son aquellas que exportan. Es decir, necesitan generar contacto con el mundo exterior, comunicando un perfil global y sólido reformulando sus estrategias de posicionamiento.

Las pequeñas empresas son la espina dorsal de la economía estadounidense. En los últimos 15 años, aproximadamente el 65\% de los nuevos empleos del sector privado fueron creados por pequeñas empresas. De acuerdo con estudios de la Comisión de Comercio Internacional de Estados Unidos (USITC), las pequeñas empresas que exportan tienden a crecer aún más rápidamente, abren más puestos de trabajo y pagan salarios más altos que las pequeñas empresas que no lo hacen ${ }^{70}$.

Estados Unidos se involucra con Brasil en cuestiones de comercio e inversión a través de varias iniciativas.

En 2011, Estados Unidos y Brasil firmaron el Acuerdo de Cooperación Comercial y Económica para aumentar la cooperación en comercio e inversión entre las dos mayores economías del Hemisferio Occidental. El acuerdo expande la relación directa de comercio e inversión, proporcionando una estructura para profundizar la cooperación en una serie de cuestiones de interés mutuo, incluyendo innovación, facilitación del comercio y barreras técnicas al comercio.

En 2016, el PIB de Brasil fue estimado en US \$ 1,8 billón (tasas de cambio actuales del mercado); el PIB real cayó cerca del 3,3\%; y la población era de 206 millones. (Fuente: FMI)

\footnotetext{
${ }^{70}$ Office of the United States Trade Representative. Recuperado el 26 de agosto de 2018 de: https://ustr.gov/
} 
El comercio de bienes y servicios de Estados Unidos con Brasil totalizó 88.200 millones de dólares en 2016. Las exportaciones de bienes y servicios de Brasil para EE.UU. fueron de 33.200 millones de dólares.

Brasil es actualmente el $14^{\circ}$ mayor socio comercial de bienes de Estados Unidos, con 56.500 millones de dólares en el total (contabilizando la exportación y la importación) de comercio de bienes durante el año 2016.

El comercio de servicios con Brasil (exportaciones e importaciones) totalizó 31.700 millones de dólares en 2016. Las exportaciones de servicios de Brasil para EE.UU. fueron de US $\$ 6.800$ millones $^{71}$.

\subsubsection{Exportaciones de servicios de Brasil a EE.UU.}

Según la Oficina del Representante de Comercio de Estados Unidos, las exportaciones de servicios de Brasil a Estados Unidos, se estima en US \$ 6.800 millones en 2016, el $13,3 \%$ (US \$ 1,0 mil millones) a menos que 2015 , pero un $125 \%$ por encima de los niveles de 2006. Las principales exportaciones de servicios de Brasil a Estados Unidos en 2015 fueron servicios de mantenimiento y reparación, propiedad intelectual (procesos industriales) y servicios profesionales y de gestión, dónde se encaja la actividad de diseño gráfico.

\subsubsection{Inversiones de Brasil en EE.UU.}

En 2014 (datos más recientes disponibles), las ventas de servicios en Estados Unidos por empresas de propiedad mayoritaria de Brasil fueron de US \$2,0 mil millones.

Según datos del consulado estadounidense en São Paulo ${ }^{72}$, la inversión brasileña en Estados Unidos aumentó un $89 \%$ en los últimos cinco años, y la tendencia es que los aportes continúen creciendo. Las razones van desde la fuga de la crisis económica y un ambiente de negocios más favorable hasta la identificación con la cultura americana y el deseo de una mejor calidad de vida. Cerca de 1,3 millones de brasileños ya residen

\footnotetext{
${ }^{71}$ Office of the United States Trade Representative. Recuperado el 26 de agosto de 2018 de: https://ustr.gov/countries-regions/americas/brazil

${ }^{72}$ Consulado Geral dos EUA São Paulo | Embaixada e Consulados dos Estados Unidos no Brasil. Recuperado el 26 de agosto de 2018 de: https://br.usembassy.gov/pt/embassy-consulatespt/saopaulo/
} 
legalmente en Estados Unidos, según el Ministerio de Relaciones Exteriores

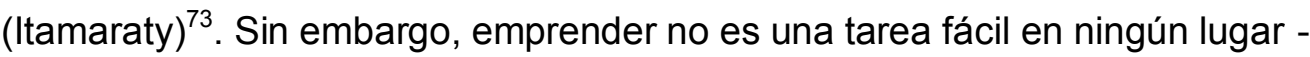
especialmente en un país con tantos negocios. Por eso, la empresa que orienta a inmigrantes a abrir negocios internacionalmente, Visa Franchise ${ }^{74}$, elaboró un estudio enfocado en el mercado estadounidense, enumerando los locales y emprendimientos con más oportunidad de éxito para los brasileños.

Según la Visa Franchise, el $90 \%$ de los brasileños que van a abrir un negocio en Estados Unidos eligen el estado de Florida como lugar de operación.

Hay varias razones detrás de la preferencia. El primer motivo es la accesibilidad hacia Brasil. El vuelo directo ayuda mucho a la hora de ir y volver a visitar la familia, por ejemplo. El segundo punto es el clima, similar al brasileño. Por último, la gran presencia de la comunidad brasileña en Florida también ayuda en la adaptación al nuevo país.

También tenemos Texas, estado americano dónde se ubica la ciudad de Austin, local dónde el autor ya posee contactos interesados en servicios de diseño gráfico, que es un estado muy grande y que presenta mucho crecimiento de los negocios. Además, en ese estado tenemos la presencia de muchos latinoamericanos, lo que facilita a la hora de empezar a pensar en la exportación de servicios. Pues apuntar en primer lugar, a una región "cercana" culturalmente hablando, permite que el emprendedor haga un análisis directo de sus puntos fuertes y débiles como exportador.

Esta estrategia es conocida como "regrocentrismo" ", que es la segmentación del mercado en niveles internacionales, los cuales tiene una estrategia para su expansión. En este caso, la estrategia es la afinidad cultural con latinoamericanos emprendedores que viven en EE.UU. como forma de empezar sistemáticamente el proceso de internacionalización del estudio.

En conclusión, y de acuerdo con el análisis estadístico y contextual de los capítulos, la definición del segmento a ser abordado se refiere a las PYMES establecidas en EE.UU., para las cuales Brasil es una alternativa accesible y reconocida por su

\footnotetext{
${ }^{73}$ Governo do Brasil - Ministério de Relações Exteriores. Recuperado el 26 de agosto de 2018 de: http://www.itamaraty.gov.br/pt-BR/

${ }^{74}$ Visa Franchise - Especialistas em Franquias para Investidores nos EUA. Recuperado el 07 de septiembre de 2018 de: https://www.visafranchise.com/

${ }^{75}$ Presentación (2014). Marketing Internacional en Mercados Internacionales, Universidad Nacional de La Plata. Profesora Dra. Cristina Zapata
} 
creatividad y soluciones osadas, además de haber pasado por situaciones adversas y 60 poseer talentos creativos en las disciplinas relevantes.

\subsection{Plan de Marketing: Servicios. (Producto)}

Los servicios prestados por el estudio son: identidad visual, embalaje, editorial, catálogos y piezas gráficas, ilustración, ambientación / señalización y diseño digital. Cada uno de ellos puede trabajar individualmente o mezclarse en proyectos integrales. También es necesario definirlos desde el perfil del estudio para profundizar su diferenciación.

La identidad visual es el conjunto de elementos formales que representa visualmente, y de forma sistematizada, un nombre, idea, producto, empresa, institución o servicio. Este conjunto de elementos suele tener como base el logotipo, un símbolo visual que se complementa en los códigos de colores, de las tipografías, en los grafismos, en personajes, en las personalidades y otros componentes que refuerzan el concepto a ser comunicado a través de esa imagen como el eslogan o tagline, frase de efecto que cumple este papel. En resumen, la identidad visual es la imagen ampliada de la marca.

La confección de un logotipo o de un símbolo visual capaz de representar un emprendimiento debe establecerse a través de un documento técnico al que los diseñadores han nombrado manual de la identidad visual. Este documento sirve para establecer normas y criterios técnicos de reproducción de la marca en los más variados soportes existentes, como los soportes gráficos (impresión) y soportes electrónicos (interfaces).

El embalaje es un recipiente o envoltura que almacena productos temporalmente y sirve principalmente para agrupar unidades de un producto, con el objetivo de crear mejores condiciones para la distribución, el transporte y el almacenamiento. Otras funciones del embalaje son: proteger el contenido, informar sobre las condiciones de manipulación, exhibir los requisitos legales como composición, ingredientes, etc. y promover el producto a través de gráficos visuales.

El diseño editorial está íntimamente ligado al periodismo. Por este motivo, el diseñador gráfico trabaja siempre en sociedad con el periodista o escritor, en el caso de libros. En general, el diseño editorial abarca la creación y diagramación de libros, revistas y periódicos. 
Los catálogos y piezas gráficas de cierta forma están relacionados con el diseño editorial, pero con objetivos más promocionales, como divulgar una nueva colección de una confección de ropa, mostrar el portafolio de una galería de arte o presentar la programación de un festival de teatro. En este segmento también se incluye todo lo que complementa la parte visual de un negocio, como un menú, un folleto, e incluso piezas digitales como publicaciones personalizadas en Facebook.

La ilustración es una imagen utilizada para acompañar, explicar, interpretar, añadir información, sintetizar o simplemente decorar un texto. Aunque el término se utiliza frecuentemente para referirse a dibujos, pinturas o collages, una composición con fotografías, por ejemplo, también es una ilustración.

Ambientación y señalización en un ambiente comercial sirve para proporcionar tanto a colaboradores, clientes y proveedores una experiencia marcada. En este sentido es necesario desarrollar con habilidad la personalización del espacio corporativo, contemplando su ambientación y señalización interna y externa, de modo estratégico y en sintonía con la Arquitectura.

Diseño Digital es una extensión de la práctica del diseño gráfico, donde el enfoque del proyecto es la creación de sitios web y proyectos digitales, como aplicaciones para celulares.

El diseño digital tiende a la multidisciplinaridad, ya que la construcción de proyectos digitales, como páginas web, requiere subsidios/complementos de diversas áreas técnicas, además del diseño propiamente dicho. Áreas como la arquitectura de la información, programación, ergonomía, usabilidad, accesibilidad entre otros.

La preocupación fundamental en proyectos de diseño digital es agregar los conceptos de usabilidad con la planificación de la persona en destaque en el uso de la interfaz, garantizando que el usuario final alcance sus objetivos de forma agradable e intuitiva.

Cada uno de los servicios descritos es abordado de manera integral por todo el equipo, para agregar ideas y estrategias, ya que no es necesario ser un especialista en diseño web, por ejemplo, para decir lo que funciona en un proyecto digital. Un usuario con un poco de conocimiento y una mirada crítica puede añadir mucho para la construcción de un sitio web ideal. 
En cuanto a la estrategia de precios, se definirá un precio de marketing orientado al mercado, teniendo como base de precios de referencia tablas sugeridas por asociaciones como la ADG - Asociación de Diseñadores Gráficos de Brasil y la Adegraf - Asociación de Diseñadores Gráficos del Distrito Federal de Brasil ${ }^{76}$. La tabla de Adegraf incluso está disponible online en el sitio web de la institución: www.adegraf.org.br. Estas asociaciones hacen una buena investigación de mercado y suelen estipular una media de precios válida y acorde con la realidad.

En el caso específico de proyectos orientados a la exportación, se hará la conversión de los valores para ya enviar la propuesta de presupuesto con precios en dólares americanos, lo que mantiene un patrón y práctica internacional, además de no perderse en valor financiero si un proyecto específico se extiende por meses, ya que el dólar es una moneda más estable que el real brasileño.

Los valores sugeridos por dichas asociaciones son bien coherentes con el perfil del estudio, de modo que podemos posicionarnos de acuerdo con el valor agregado del servicio.

De la misma forma, estrategias específicas serán realizadas de acuerdo con el servicio, el tamaño de la empresa y los requisitos del proyecto que terminarán en múltiples precios.

La definición de la política de precios mantendrá la coherencia interna y externa, donde el precio y el valor percibido están relacionados, teniendo en cuenta las percepciones del cliente asociadas a una imagen de calidad.

\subsection{Distribución (Plaza)}

En relación a la estrategia de canales, esbozamos varias puertas de entrada para la penetración.

Primero haciendo parte de asociaciones profesionales que estimulan la internacionalización de empresas y la exportación de servicios de diseño a través de

\footnotetext{
${ }^{76}$ ADEGRAF - Tabela referencial de valores 2016/2018. Recuperado el 26 de agosto de 2018 de: https://docs.wixstatic.com/ugd/819e53_64a1447f6e234ee79612f012c49dd43e.pdf
} 
entrenamientos y capacitaciones, como es el caso de ABEDESIGN - Asociación

Brasileña de Empresas de Diseño ${ }^{77}$.

Otra puerta de entrada es inscribiendo la empresa en programas de calificación para la exportación de servicios, como es el caso de la ApexBrasil - Agencia Brasileña de Exportaciones e Inversiones ${ }^{78}$, que posee el programa PEIEX - Programa de Calificación para Exportación ${ }^{79}$, que busca calificar empresas para convertirse en exportadoras a través de la consultoría individualizada, entrenamientos y capacitaciones, y con la organización de visitas técnicas a los países en que se pretende establecer negocios.

Otro punto es participar en entrenamientos y misiones de negocios del SEBRAE Servicio Brasileño de Apoyo a las Micro y Pequeñas Empresas ${ }^{80}$, servicio social autónomo brasileño que objetiva auxiliar el desarrollo de micro y pequeñas empresas, estimulando el emprendedor en Brasil.

Incluso en el año 2000, SEBRAE y la SBA - Small Business Administration ${ }^{81}$, institución que así como el SEBRAE en Brasil, es un servicio de apoyo para micro y pequeñas empresas de Estados Unidos, principalmente en lo que se refiere a la importación y exportación, celebraron un protocolo de intenciones con el objetivo de promover el intercambio entre pequeñas empresas norteamericanas y brasileñas visando el desarrollo económico y comunitario entre ellas ${ }^{82}$.

Vale comentar que EE.UU. es un destino popular para Brasil cuando se habla de viajes de misión de negocios. Instituciones como ApexBrasil, SEBRAE y AMCHAM - Cámara Americana de Comercio en Brasil, siempre arreglan viajes a este destino.

En este punto, es esencial enfatizar la formación de la cultura organizacional para transmitir desde el principio el perfil diferencial del estudio y trabajar externamente, pero

\footnotetext{
77 ABEDESIGN - Associação Brasileira de Empresas de Design. Recuperado el 07 de septiembre de http://abedesign.org.br

${ }^{78}$ ApexBrasil - Agência Brasileira de Exportações e Investimentos. Recuperado el 07 de septiembre de http://www.apexbrasil.com.br/home/index

${ }^{79}$ PEIEX - Programa de Qualificação para Exportação. Recuperado el 07 de septiembe de http://www.apexbrasil.com.br/qualifique-sua-empresa-peiex

80 SEBRAE - Serviço Brasileiro de Apoio às Micro e Pequenas Empresas. Recuperado el 07 de septiembre de http://www.sebraepr.com.br/PortalSebrae

${ }^{81}$ U.S. Small Business Administration. Recuperado el 07 de septiembre de https://www.sba.gov/

82 SEBRAE - Conheça o "SEBRAE" dos Estados Unidos. Recuperado el 07 de septiembre de http://sites.pr.sebrae.com.br/blogs/2014/05/14/conheca-o-sebrae-dos-estados-unidos/
} 
con el espíritu de pertenecer a un estudio creativo que trabaja pro activamente para alcanzar las metas y objetivos de cada proyecto.

En el siguiente punto, diferentes patrones serán definidos a través del mix de comunicación. Lo que también afectará la forma de entrada para la internacionalización de los servicios de diseño gráfico.

\subsection{Comunicación (Promoción)}

El mix de comunicación tiene algunos puntos fuertes en particular por ser un estudio de diseño con experiencia en la generación de campañas digitales (Facebook, Instagram, y Google Adwords) y publicitarias (apoyo a eventos, por ejemplo). Esto debe ser una fuerza para aprovechar al máximo en la planificación de un mix con el objetivo de alcanzar el público objetivo a través de publicidad y marketing.

Una estrategia bien clara y objetiva es definida en la cual el esfuerzo es directamente concentrado en el consumidor final del servicio. El estudio tiene un sitio web en inglés en el que se puede navegar y conocer todos los servicios con casos reales. La promoción del sitio a través de Google Adwords, por ejemplo, es fundamental para presentar la empresa como teniendo un perfil corporativo, creativo, experimentado, solvente y sólido. De la misma forma, elaboramos campañas de marketing digital, publicando nuevos trabajos y contenidos relevantes por lo menos dos veces por mes. Esto va a crear sinergia con los siguientes puntos del mix de comunicación que buscan alcanzar un posicionamiento a corto plazo de la empresa como un estudio de diseño brasileño internacional.

La presencia online en las redes sociales en general: Facebook, Instagram y Linkedin y en las específicas de la categoría creativa como Behance y Dribbble; significa tener varios canales abiertos a la llegada e interacción con el público objetivo y con el mercado en general.

Aun hablando de las redes sociales, estar actualizado siguiendo a los principales estudios que definen tendencias nos permite actualizarnos con conocimientos y tendencias y reinterpretarlos para aplicar a nuestro caso específico. Las directrices de publicidad en Facebook y Google Adwords con segmentación acordada (PYMES de EE.UU. de los estados de Florida y Texas) se han configurado y agregado a una campaña de marketing por correo electrónico personalizada para proporcionar información valiosa en cada 
envío. La base de datos de la misma estará compuesta por las empresas registradas en las cámaras de comercio y en las cámaras de exportadores de EE.UU..

Por otra parte, la presencia activa en iniciativas de internacionalización, como en la ya citada APEX Brasil - Agencia Brasileña de Promoción de Exportaciones e Inversiones, generando intercambio de reuniones y alianzas estratégicas que permitan aumentar la visibilidad del estudio en el mercado local y en los mercados potenciales extranjeros. Además de participar de las misiones de negocios arregladas por estas instituciones, por lo menos una vez por año, para conocer la cultura empresarial y generar contactos.

Asistencia anual a eventos comerciales donde nuevos productos son promovidos y presentados, donde las marcas son presentadas y el mercado regional y global es conocido. Enfocado en segmentación de mercado, como Ferias Internacionales de Emprendedores. Muchas ferias internacionales acontecen en São Paulo, ciudad que está a solamente $400 \mathrm{~km}$ de Curitiba, ciudad sede del estudio. Algunos ejemplos son la Rakuten Expo 2018, y la Feria del Emprendedor del SEBRAE SP.

Es válido arreglar un buen material académico para blogs y conferencias especializadas en eventos del sector y / o sectores relacionados, demostrando la experiencia y las historias de éxito del estudio, diferenciales, metodología, proceso de trabajo, casos de referencia.

También se visualiza la creación de estrategias de InBound Marketing, o sea, estrategias de marketing que apuntan a atraer el interés de las personas. También llamado marketing de atracción, la idea sería utilizar de sus tres grandes pilares: SEO, a través de campañas orientadas en Google AdWords. El marketing de contenidos, tales como la publicación de un libro electrónico (e-book) y estrategias orientadas al público específico en las redes sociales.

Un ejemplo de estrategia de InBound Marketing puede ser la publicación y promoción de un e-book para bajar en el sitio web del estudio, que como el propio nombre dice, es un libro digital, lo que no acarrea costos con impresión. El e-book puede ser dispuesto en distintas lenguas y la base para la creación de este libro puede ser el contenido que el autor ya ha utilizado en una palestra que impartió sobre el tema "Branding y Gestión de Marcas", que trataba de estrategias de branding para apalancar PYMES. Esta es una manera de traer visibilidad para el estudio y generar reconocimiento dentro y fuera del país. 


\section{CAPÍTULO 4: Sistema de control para supervisar el progreso del plan de marketing internacional.}

\subsection{Plan de acción. Implementación.}

El trabajo se basará en el modelo Lean Start Up, que define un producto mínimo viable (MVP) y está totalmente acorde con el modelo VUCA. O sea, continuamente abierto para modificar, cambiar y reformular aspectos que sean necesarios para centrarse en cómo construir valor en la unidad estratégica de internacionalización del estudio. De la misma forma, el circuito principal del modelo: crear, medir, aprender, nos permitirá ajustar y reformular los aspectos necesarios para que el aprendizaje validado y el feedback sean dos pilares fundamentales en la ejecución e implementación del plan, promoviendo la innovación continua.

La parte de atención al cliente del estudio debe absorber este primer contacto, y también será responsable por el área de Marketing Internacional, orientado a la administración de negocios internacionales, con un papel asociado a la disciplina de diseño y al mismo tiempo con capacidades de comunicación y marketing internacional.

De la misma forma, se harán contactos que puedan actuar como freelancers en el país, ayudando a los clientes en reuniones presenciales, si se hace necesario.

Contaremos también con asesoría especializada en la legislación y reglamentación tributaria de EE.UU. por profesionales especializados en derecho internacional. Esta asesoría es dispuesta por AMCHAM - Cámara de Comercio Brasil EE.UU. ${ }^{83}$. Creada como una clásica cámara de comercio, Amcham Brasil se ha convertido en una entidad de alcance más amplia y tiene su actuación basada en dos pilares centrales: defensa de la libre iniciativa privada en Brasil y de las relaciones entre el país y Estados Unidos.

El espacio físico estará ubicado en la ciudad de Curitiba - Brasil, en el local actual del estudio: Calle Major Vicente de Castro, 2286 - cj.09, CEP: 81.030-020, Curitiba - Paraná Brasil.

\footnotetext{
${ }^{83}$ AMCHAM. Recuperado el 08 de septiembre de https://www.amcham.com.br/curitiba
} 


\subsection{Implementación del Plan de Marketing}

\subsubsection{Primera etapa}

En el inicio habrá un foco en la promoción: o sea, divulgar el estudio y posicionarlo en el mercado objetivo, con énfasis especial en la ejecución de la estrategia de comunicación:

- Email Marketing Campaign: dos remesas por mes durante seis meses; temas específicos relacionados con estrategias de Inbound Marketing, contribuciones teóricas y tendencias de diseño en PYMEs y cómo el diseño gráfico puede mejorar los negocios;

- Envío de Folleto con portfolio de servicios y ejemplos de casos de éxito para empresas especialmente seleccionadas por su perfil y contacto con distribuidores junto a un regalo especialmente creado para la promoción del estudio (en el final o en el comienzo del año, por ejemplo, puede ser un calendario impreso e ilustrado, con temática de negocios)

- Artículos en medios especializados: sobre el impacto del diseño en el desempeño de las empresas; blogs especializados en diseño, comunicación, marketing y consultoría de sentido común sobre diseño gráfico y tendencias visuales para impactar clientes;

- Presencia en ferias, eventos del sector y misiones de negocios, con una propuesta innovadora que genera curiosidad tanto en el público objetivo como en el público en general.

- Viajes al mercado de destino, encuentros, eventos y reuniones, cursos y workshops con proveedores, colegas de negocios y empresarios.

\subsubsection{Segunda etapa}

De acuerdo con lo que fue experimentado en la primera etapa, los ajustes relevantes serán hechos y los vínculos con los clientes adquiridos por medio de estrategias de fidelización serán profundizados. Al mismo tiempo delineando acciones específicas, se continuará la comunicación, patrocinio o apoyo a eventos y ferias y presencias académicas a través de conferencias y / o cursos y workshops sobre temas específicos, para alcanzar sinergia con la fase anterior y posición como un estudio de diseño brasileño, con mucho know-how y especialista en proyectos de alta calidad. 
- Reuniones presenciales o virtuales con grupos de clientes externos relacionados para 68 hablar sobre la experiencia y el desempeño de la aplicación del diseño estratégico en sus empresas;

- Participar de misiones de negocios en EE.UU. para nutrir la cultura, aprender más sobre los sectores productivos y de servicios para desarrollar nuevas propuestas;

- Acompañamiento personalizado de los proyectos realizados e investigación de satisfacción del cliente, con una mirada post-proyecto que nos permite reflexionar sobre aspectos de la metodología trabajada y revisar aquellos que deben ser reformulados.

- Revisión financiera de la inversión y beneficios, ajustes de presupuestos y (si es el caso) definición de la nueva inversión. 


\section{CAPÍTULO 5: Conclusiones}

\subsection{Conclusiones del Plan de Marketing Internacional}

Cada parte integrante del mix de marketing es importante para generar un plan sinérgico y solvente que busca la internacionalización del estudio con bases estables y que permita adaptarse y superar con el tiempo. El plan de marketing internacional permite que el estudio tenga una planificación clara sobre los principales puntos para alcanzar el objetivo:

- proporcionar sus servicios de manera diferenciada: proyectos de alta calidad con el valor agregado de los conocimientos de marketing y de la consultoría creativa;

- visar un segmento con gran potencial: PYMES de EE.UU. que exportan o quieren exportar;

- posicionarse con un precio dentro del promedio sugerido por asociaciones profesionales específicas, que connota profesionalismo, actualización con el área de trabajo y la calidad del servicio;

- penetrar en los mercados a través de diferentes canales de acceso: directa (prospección activa de clientes) o indirectamente (redes sociales, participación en eventos);

- fuerte desarrollo en promoción y comunicación con acciones específicas de presencia de marca, posicionamiento de perfil especialista, contacto continuo con el ambiente de negocios para promover alianzas y acercamiento de clientes con foco en la flexibilidad, comunicación y feedback.

Basado en el modelo Lean Start Up, significa que el estilo de implementación de cada acción del Plan de Marketing Internacional desarrollado debe ser permeable a la autoevaluación constante y puede ser rápidamente reformulado para ejecutar de forma rápida y optimizada y así fortalecer los resultados. Así que es esencial estar abierto y 
atento al surgimiento de nuevas oportunidades y detectar eventuales fallas en cada proyecto.

\subsection{Conclusiones Generales}

En franca expansión y con grandes perspectivas de crecimiento, el mercado internacional de servicios requerirá preparación, respuestas rápidas y versatilidad por parte de las empresas de servicios. Aunque la exportación de servicios aún está en el comienzo, tiene un gran potencial debido a nuevas características del mundo actual: facilidad de comunicación, flexibilidad, y el talento que ahora no queda más restricto a una cierta región. El diseño gráfico sigue cada vez más siendo considerado como un valor agregado necesario para mejorar el rendimiento de los negocios.

Vamos a desarrollar la presencia de exportación del estudio teniendo como referencia a los profesionales o estudios de diseño gráfico que ya hacen la exportación de sus servicios de manera estructurada y continuada.

Se aprovechará de todas las fortalezas del estudio en este contexto, debido a la calidad de la cultura corporativa, a la adaptabilidad a condiciones adversas y la capacidad de decodificar la necesidad del cliente y proporcionar un producto (identidad visual, embalaje, diseño editorial, catálogos y piezas gráficas, ilustración, ambientación y señalización o diseño digital) que vaya más allá de lo que se ha imaginado o esperado.

Vamos a centrarnos en la experiencia del estudio en diseño de comunicación que alcanza ventajas competitivas para implementar la estrategia de concentración del mercado, buscando a pequeñas y medianas empresas con características similares de EE.UU. en un primer momento, identificando el punto correcto y el fracaso para agregar valor a cada proyecto.

El estudio tendrá como objetivo la entrada en el mercado internacional a través del desarrollo de una serie de iniciativas a largo plazo sobre la base de la calidad de los servicios prestados, que producen fuertes lazos con empresas de diferentes sectores y negocios complementarios, colegas y potenciales agentes y canales "distribuidores".

Para ello delineamos este plan de marketing que se caracteriza por su capacidad de adaptarse y repensar aspectos que sean necesarios, siendo revisto y actualizado con frecuencia de acuerdo con los eventos y necesidades de cambio que puedan surgir, 
siempre respondiendo con una estrategia en tiempo real. O sea, con el seguimiento del71 plan, vamos a concentrarnos en hacer ajustes, cambios y cualquier acción que implique la buena ejecución de la estrategia propuesta.

La unidad de negocios será complementaria al operativo del estudio, junto con su propia personalidad como parte de la estrategia creativa para posicionarse en el mercado: servicios de diseño gráfico de alta calidad y patrón internacional. Vamos a promover el estilo del estudio basado en la empatía, la diversión, el espíritu emprendedor y la participación en la gestión y estrategia de las empresas.

Enfatizaremos el valor agregado del perfil del estudio: interpretando y descubriendo las necesidades de los clientes, reaccionando a ellos con propuestas innovadoras y diferenciadas, volcadas hacia resultados que de hecho harán la diferencia en términos financieros, pues diseño es inversión.

Se dice que nadie hace nada a partir de la nada, por eso la importancia del desafío de la tesis para desarrollar, en ese caso, habilidades de marketing internacional.

El gran problema es que intentamos definir cosas en términos que se adecuen a nuestra visión del mundo. Como dijo una vez el psicólogo Abraham Maslow, "si tienes un martillo en la mano, tiende a ver el mundo como clavos". Esta idea de extender las fronteras más allá del contexto existente - el pensar fuera de la caja - es de crucial importancia en el mundo de los negocios, y aún más importante en el mundo ultra conectado de hoy día. En realidad, la primera regla del mundo de los negocios es: si el viejo contexto no está funcionando, encuentre uno nuevo. A veces, esto es muy simple, basta reconocer que lo que no está prohibido está permitido.

El estudio es una PYME, prestadora de servicios brasileña, que enfrenta el desafío de exportar. Tiene la apertura para reconocer sus puntos fuertes y su capacidad de generar negocios internacionales, apalancados por una red de contactos y un equipo con pasado fuerte y favorables. Ahora también, tiene una herramienta estratégica que le permitirá alcanzar su objetivo de forma continuada y estable a lo largo del tiempo: el plan de marketing internacional aquí desarrollado. 


\section{Bibliografía}

Bierut, M. (2015). How to Use Graphic Design to Sell Things, Explain Things, Make Things Look Better, Make People Laugh, Make People Cry, and (Every Once in a While) Change the World. ( $\left.1^{\mathrm{a}} \mathrm{ed}\right)$ London: Harper Design.

Fernández, M. S. G. (2014). UF1783: Plan e informes de marketing internacional. ( $1^{\mathrm{a}}$ ed) Antequera, España: Ed. IC Editorial.

Goswami, A. G., Mattoo, A., Saez S. (2012). Exporting Services: A Developing Country Perspective (Trade and Development). ( $1^{\mathrm{a}}$ ed) Washington: World Bank Publications.

Junior, S.S. , Kawamura, K. (2001). Portfólio de Marcas. (1ª. ed.) Curitiba: Ed. Lúmen Design.

Krug, S. (2014). Don't Make Me Think, Revisited. A Common Sense Approach to Web Usability. ( $1^{\mathrm{a}}$ ed) Indianapolis: Ed. New Riders.

Mallo, J. G. (2015). UF1783 - Plan e informes de marketing internacional. Certificado de Profesionalidad. Marketing y Compraventa Internacional (COMM0110). ( ${ }^{\mathrm{a}} \mathrm{ed}$ ) Madrid: Ed. Elearning.

Piqueira, G. (2004). Morte aos Papagaios. (1ª . ed.) São Paulo: Ed. Ateliê Editorial.

Ries, E.; (2012). A Startup Enxuta. (1 ${ }^{\mathrm{a}}$ ed) Lisboa: Ed. LeYa.

Rocha, A.; Mello, R.C; Silva, J.F. (2009). Internationalization patterns of Brazilian service firms. In: Ramsey, J.; Almeida, A. (2009) The rise of Brazilian multinational firms. Rio de Janeiro: Ed. Elsevier.

Schwab, K. (2016). A Quarta Revolução Industrial. (1ª ed) São Paulo: Ed. Edipro.

Soto, D. (2012). Know Your Onions - Graphic Design: How to Think Like a Creative, Act like a Businessman and Design Like a God Paperback. ( $1^{\text {a }}$ ed) Amsterdam: Bis Publishers. 
Taborda, F., Wiedermann J. (2008). Latin America Graphic Design. (1ª ed) Cologne, Germany: Taschen.

Viejo, L. M. C. (2014). UF1783: Plan e informes de marketing internacional. (1 $\left.{ }^{\mathrm{a}} \mathrm{ed}\right)$ Madrid: Ed. Paraninfo.

Zimmer C. (2014). Importação e Exportação de Serviços e Intangíveis. (1ª ed) São Paulo: Ed. Fiscosoft. 
15 datos (y un mapa) sobre el peso del español en EEUU que Donald Trump debería ver. Recuperado el 22 de julio de 2018 de https://www.lainformacion.com/mundo/Datos-espanol-Estados-Unidos-DonaldTrump_0_992901230.html

ABEDESIGN - Associação Brasileira de Empresas de Design. Recuperado el 07 de septiembe de http://abedesign.org.br

A Conversation with Khoi Vinh, Principal Designer, Adobe // Design Driven NYC. Recuperado 29 de julio de 2018 de https://www.youtube.com/watch?v=u3D4HCq5Cac

ADEGRAF - Tabela referencial de valores 2016/2018. Recuperado el 26 de agosto de 2018 de: https://docs.wixstatic.com/ugd/819e53_64a1447f6e234ee79612f012c49dd43e.pdf

Agência Brasil. Presidente da AEB reclama protagonisno do comércio exterior .

Recuperado el 31 de julio de 2018 de:

http://agenciabrasil.ebc.com.br/economia/noticia/2018-07/presidente-da-aebreclama-protagonisno-do-comercio-exterior\#

Agreste - Recuperado el 23 de Agosto de 2018 de https://www.designideas.pics/agreste/

AIGA - The professional association for design. Recuperado 29 de julio de 2018 de https://www.aiga.org/

AMCHAM. Recuperado el 08 de septiembre de https://www.amcham.com.br/curitiba

ApexBrasil - Agência Brasileira de Exportações e Investimentos. Recuperado el 07 de septiembe de http://www.apexbrasil.com.br/home/index

Banco Central do Brasil. Recuperado el 22 de Julio de 2018 de https://www.bcb.gov.br/ptbr/\#!/home 
Banco Central do Brasil. Recuperado el 31 de julio de 2018 de https://economiadeservicos.com/2017/05/30/comercio-exterior-de-servicos-o-quevem-pela-frente/

BNDES - O banco nacional do desenvolvimento. Recuperado el 22 de Julio de 2018 de https://www.bndes.gov.br/wps/portal/site/home

Brand Dropro: drops of creative solutions - Recuperado el 23 de Agosto de 2018 de https://www.amazon.com/s/field-keywords $=9781388585860$

Brasil quer aumentar exportações de serviços. Recuperado el 22 de Julio de 2018 de http://www.brasil.gov.br/economia-e-emprego/2017/04/brasil-quer-aumentarexportacoes-de-servicos

Brazil's design scene reveals more than just soccer and samba. Recuperado 18 de agosto de 2018 de https://www.creativebloq.com/computer-arts/brazils-designscene-reveals-more-just-soccer-and-samba-61411957

BRICS 2018 - What is BRICS? Recuperado el 07 de septiembre de http://www.brics2018.org.za/what-brics

Casa Rex. (2017). Recuperado el 15 de octubre de 2017 de http://http://www.casarex.com/

Case Study: WalkNYC Pedestrian Wayfinding. Recuperado 29 de julio de 2018 de https://www.aiga.org/aiga/content/why-design/aiga-case-studies/justified2014/case-study-walknyc-pedestrian-wayfinding/

Consulado Geral dos EUA São Paulo | Embaixada e Consulados dos Estados Unidos no Brasil. Recuperado el 26 de agosto de 2018 de: https://br.usembassy.gov/pt/embassy-consulates-pt/saopaulo/

DFKI - German Research Center for Artificial Intelligence. Recuperado el 22 de Julio de 2018 de https://www.dfki.de/web 
Entenda como funciona o mercado de crédito de carbono. Recuperado 22 de julio de 76 2018 de http://www.brasil.gov.br/editoria/meio-ambiente/2012/04/entenda-comofunciona-o-mercado-de-credito-de-carbono

Érico Almeida - Graphic Designer. Recuperado 29 de julio de 2018 de http://www.ericoalmeida.com

Estúdio Colletivo de Design. Recuperado 18 de agosto de 2018 de https://www.colletivo.com.br/

Folha de São Paulo - Brasil perde soft power por frustrar expectativas, diz pesquisadora. Recuperado el 31 de julio de 2018 de: https://www1 .folha.uol.com.br/mundo/2017/08/1912664-brasil-perde-soft-powerpor-frustrar-expectativas-diz-pesquisadora.shtml

FMI, World Economic Outloook Database (abril de 2017). * Estimativa del FMI. International Trade Center (2017). Recuperado 22 de julio de 2018 de http://www.funag.gov.br/ipri/index.php/o-ipri/47-estatisticas/94-as-15-maioreseconomias-do-mundo-em-pib-e-pib-ppp

Governo do Brasil - Ministério de Relações Exteriores. Recuperado el 26 de agosto de 2018 de: http://www.itamaraty.gov.br/pt-BR/

Guia Básico para a Exportação de Serviços - Versão Revisada - Julho 2017. Recuperado el 31 de julio de 2018 de http://www.mdic.gov.br/images/REPOSITORIO/scs/decin/Guia_B\%C3\%A1sico/Gu ia_B\%C3\%A1sico_-versao_2017.pdf

Guilherme Marconi - Ilustrador. Recuperado 18 de agosto de 2018 de https://www.behance.net/marconi

Harvard Business Review - What VUCA Really Means for You. Recuperado 01 de septiembre de 2018 de https://hbr.org/2014/01/what-vuca-really-means-for-you

How Curitiba's BRT stations sparked a transport revolution - a history of cities in 50 buildings, day 43. Recuperado 18 de agosto de 2018 de 
https://www.theguardian.com/cities/2015/may/26/curitiba-brazil-brt-transportrevolution-history-cities-50-buildings

Icepem - Instituto de Consultoria e Elaboração de Projetos Educacionais do Mercosul Recuperado el 23 de Agosto de 2018 de: http://icepem.com.br

Idea Fixa - Canal de inspiração e expressão. Recuperado 29 de agosto de 2018 de https://www.ideafixa.com

Indústria, Comércio Exterior e Serviços - Estatísticas do Comércio Exterior de Serviços 2016 . Recuperado el 22 de julio de 2018 de: http://www.mdic.gov.br/index.php/comercio-servicos/estatisticas-do-comercioexterior-de-servicos/2555-estatisticas-do-comercio-exterior-de-servicos-2016

International Trade Center (2017). Trade Map - International Trade Statistics - List of exported services for the selected service. Recuperado 31 de diciembre de 2017 de

https://www.trademap.org/tradestat/Service_SelService_TS.aspx?nvpm=1|||||||S00 $|1| 3|1| 2|2| 1|5| 1 \mid 1$

Kako Illustrator. Recuperado 18 de agosto de 2018 de http://www.kakofonia.com/

Las exportaciones de servicios de América Latina y su integración en las cadenas globales de valor. Recuperado el 22 de Julio de 2018 de http://www.eclac.org/publicaciones/xml/3/35963/DocW37fin.pdf

Meio \& Mensagem - O bem sucedido modelo do estúdio Colletivo. Recuperado el 31 de julio de 2018 de: http://www.meioemensagem.com.br/home/comunicacao/2012/12/19/o-bemsucedido-modelo-do-estudio-colletivo.html

Missile - Energy Drink Identity. Recuperado 18 de agosto de 2018 de https://www.behance.net/gallery/280878/Missile-Energy-Drink-Identity

Mulheres Barbadas. Recuperado 18 de agosto de 2018 de http://mulheresbarbadas.tumblr.com/ 
Museu Oscar Niemeyer - Museum precariously perched on a massive yellow pillar.

Recuperado 18 de agosto de 2018 de

https://www.atlasobscura.com/places/museu-oscar-niemeyer

Office of the United States Trade Representative. Recuperado el 26 de agosto de 2018 de: https://ustr.gov/

PEIEX - Programa de Qualificação para Exportação. Recuperado el 07 de septiembe de http://www.apexbrasil.com.br/qualifique-sua-empresa-peiex

Petrobras - Pre Sal. Recuperado el 31 de julio de 2018 de:

http://www.petrobras.com.br/pt/nossas-atividades/areas-de-atuacao/exploracao-eproducao-de-petroleo-e-gas/pre-sal/

Pierini Branding for the World. (2017). Recuperado el 15 de octubre de 2017 de http://www.pierinipartners.com/

Por que tantos países torcem para o Brasil em Copa do Mundo. Recuperado el 22 de Julio de 2018 de https://exame.abril.com.br/mundo/por-que-ha-tantos-paisestorcendo-para-o-brasil-na-copa-do-mundo-da-russia/

Programa de Qualificação para Exportação - PEIEX. Recuperado 31 de julio de 2018 de http://www.apexbrasil.com.br/qualifique-sua-empresa-peiex

Robinsson Cravents - Creative Director / Graphic Designer / Illustrator (2018).

Recuperado 18 de agosto de 2018 de https://www.behance.net/robinssoncravents

Sebrae - Como Exportar Serviços: Características e Desafios. Recuperado el 22 de Julio de 2018 de https://bibliotecas.sebrae.com.br/chronus/ARQUIVOS_CHRONUS/bds/bds.nsf/2D 154BF8654781578325784500091797/\$File/NT000453DE.pdf

SEBRAE - Conheça o "SEBRAE" dos Estados Unidos. Recuperado el 07 de septiembre de http://sites.pr.sebrae.com.br/blogs/2014/05/14/conheca-o-sebrae-dos-estadosunidos/ 
SEBRAE - Serviço Brasileiro de Apoio às Micro e Pequenas Empresas. Recuperado el 79 07 de septiembre de http://www.sebraepr.com.br/PortalSebrae

Serviços 2016 - Panorama do Comércio Internacional. Recuperado el 22 de Julio de 2018 de http://www.mdic.gov.br/images/REPOSITORIO/scs/decin/Estat\%C3\%ADsticas_de _Com\%C3\%A9rcio_Exterior/2016/Panorama_Oficial_2016_Final_.pdf

Story of cities \#37: how radical ideas turned Curitiba into Brazil's 'green capital'.

Recuperado 18 de agosto de 2018 de https://www.theguardian.com/cities/2016/may/06/story-of-cities-37-mayor-jaimelerner-curitiba-brazil-green-capital-global-icon

U.S. Small Business Administration. Recuperado el 07 de septiembre de https://www.sba.gov/

Visa Franchise - Especialistas em Franquias para Investidores nos EUA. Recuperado el 07 de septiembre de 2018 de: https://www.visafranchise.com/

Welcome to the Soft Power 30. Recuperado el 22 de Julio de 2018 de https://softpower30.com/

What is digital commoditization? Recuperado el 28 de julio de 2018 de https://www.linkedin.com/pulse/what-digital-commoditization-jorge-arbache/?trk=vfeed\&lipi=urn\%3Ali\%3Apage\%3Ad_flagship3_detail_base\%3BZ2lkPuArX\%2FAC MS2Rbz\%2Ff9Q\%3D\%3D

World Bank. Recuperado el 31 de julio de https://data.worldbank.org/indicator/NY.GDP.MKTP.CD?locations=BR 
Presentación (2014). Marketing Internacional en Mercados Internacionales, Universidad Nacional de La Plata. Profesora Dra. Cristina Zapata.

Presentación (2014). Estrategias y políticas de Precio, Universidad Nacional de La Plata. Profesor Alberto Albarellos.

Presentación (2014). Políticas de Comunicación, Universidad Nacional de La Plata. Profesor Juan Katz.

Presentación (2015). Administración Estratégica de la Firma, Universidad Nacional de La Plata. Profesor José Pagano. 
Anexo I - Briefing/Questionnaire

ÉRICO

ALMEIDA

RAPHIC

ESIGNER

1. What is your brand name? What is the meaning behind its name?

2. What is your tag line? What is the meaning behind the tag line?

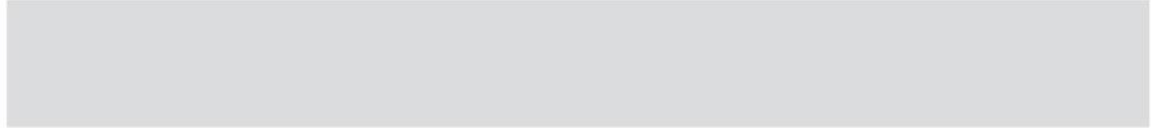

3. What is the purpose of your brand?

4. What is the vision for your brand in the future?

5. Does your brand have a history or a story?

6. Why do you want a new brand (for rebranding)? What do you want your new brand to accomplish?

7. What are $3-5$ core values of your brand? 
R A P H I C

8. If you imagine your brand as a person, what personality traits would they have?

9. Who is your dream client or target audience?

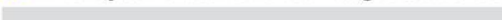

9. Who isyour dream client or target audience?
\end{abstract}

10. What problems do your brand face?

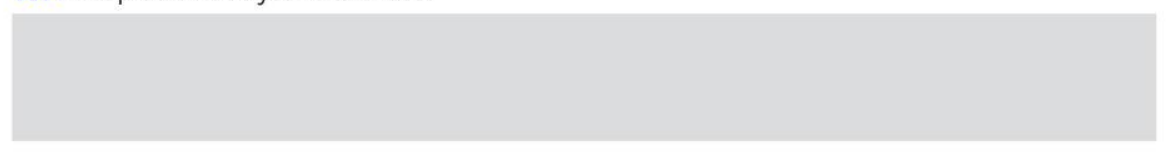

11. How does your brand differ from other brands in your industry?

12. Why should someone choose your brand over another? Describe the value your brand adds to your clients (Value proposition).

13. Who are your competitors? How are these brands better than you?

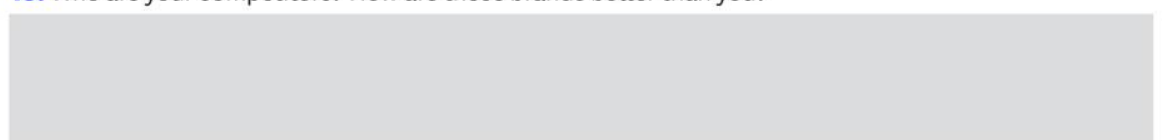

14. List examples (images/links) where you've seen fonts and typograhy that you liked.

Rua Major Vicente de Castro, n²286 - cj. 09 | CEP: 81.030-020 | Fanny | Curitiba . PR. Brasil fone: +55 413569.6984 | +55 4199948.4283 | CONTATO@ERICOALMEIDA.COM | WWW.ERICOALMEIDA.COM 
R A P HIC

DESIGNER

ALMEIDA

15. Do you have any color preferences? WHat colors should be avoided? Include examples (images/links) of colour usage that you liked.

16. What three brands do you Love and why?

17. List what you would like to preserve from your current brand if any and explain why.

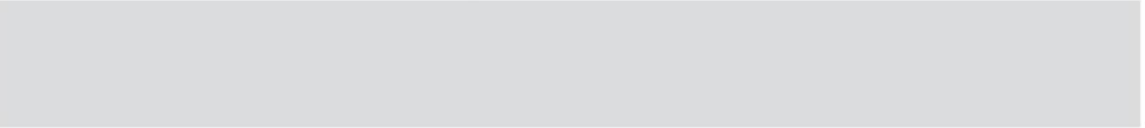

18. What materials should be created beyond the brand? (Stationery, packaging, etc.)

19. Share any additional details or considerations about your project.

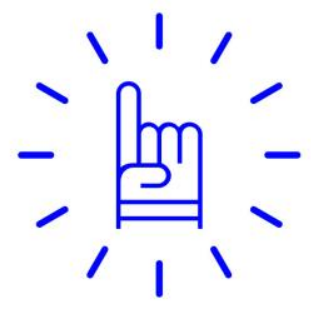

\section{O N G R A T U L A T I O N S !}

You've reached the end of the questionnaire.

If you are able to answer most of these questions with ease, well done! You now have the ingredients to create an awesome brand!

If you struggled with some of them or are unhappy with some of your current answers, no worries. You now also have the insights to help shape your brand and steer it in the direction you truly want.

\section{Need a helping hand for your brand or} more creativity for your company?

Just drop us an email at contato@ericoalmeida.com to set up a meeting or visit our website at www.ericoalmeida.com to find out more about us and the clients we have helped.

Rua Major Vicente de Castro, n²286 - cj. 09 | CEP: 81.030-020 | Fanny | Curitiba . PR. Brasil fone: +55 413569.6984 | +55 4199948.4283 | CONTATO@ERICOALMEIDA.COM | WWW.ERICOALMEIDA.COM 
RAPHIC

ALMEIDA

ESIGNER

Client: Aura Stewart

quo. 032015A

Ref.: Nutrichildren - Labels/Brand Adaptation

As requested, here is the proposal to create basis for labels, and a brand adaptation for Nutrichildren, described below:

1.Creating a Brand Adaptation for Nutrichildren - "Nutrichildren for Picky Eaters",

1.1 Research/References Analysis

1.2 Routes, development of designs, color tests, reduction, typography,

design application tests.

1.3 Presentation of the proposal

1.4 Changes (if it's necessary)

1.5 Delivery of the final archive

1. Creating basis for Labels

1.1 Research/References Analysis.

1.2 Routes, development of concepts and designs, color pallete and texture tests.

1.3 Presentation of the proposals.

1.4 Changes (if it's necessary).

1.5 Delivery of the final archives.

FEES

Professional fees for the services asked are paid for the amount of:

1. Brand adaptation project

1. Basis for labels.

US\$190,00

TOTAL

PAYMENT TERMS

In 2 parcels: US $\$ 230,00$ to start the work and US $\$ 230,00$ for 30 days.

* Payments made via PayPal. 

ERICO craphic
ALMeida designer

1. It's not included costs not mentioned in the project description (such as photo service, use of images, creation and revision of texts, scans, impressions, mockups and print productions costs).

2. With the formal approval of the quotation, via electronic mail, the contracted company commits the presentation of a pre project following the description of the briefing. The usual deadline for submission of this pre project is 15 working days from the approval of the quotation. Based on the pre project will be proceed all the necessary corrections until the project is finalized with the approval of the final layout. After the approval of the final layout will be charged separately any new corrections.

3. This quotation is limited to the description of the briefing. Briefing changes subsequent to the approval of the quotation implies a new quotation proposal.

4. In case of express or implied cancellation of the project by the contracting company, after the presentation of a pre project, the contracting agrees to pay $50 \%$ of the total quotation amount. It will be considered cancellation of the project by the contracting company, if it does not manifest itself in favor of its ongoing for more than 60 days.

5. The project is completed after the formal approval, performed by electronic mail, of the final layout, the contracted must provide within 3 working days, a CD with the final design arts or a link to download the files.

6. With the delivery of the final designs, cease the responsibilities of the contracted on the production of the project, except when the contracting company chooses the production follow-up performed by the contracted based on one of the quotation submitted by the contracted.

7. The material liability by the contracted will be restricted to the amount of the total quotation.

8. Although the rights of use of the illustrations will be passed to the contracting, it undertakes to require formal and prior authorization of the contracted to change, do adaptations or use for other purposes.

9. The contracted agrees with the duty of confidentiality of information related to the project, and also assumes that is developing an original artworking, never published before.

10. This quotation proposal is valid for 30 days.

I am available for any clarification needed.

All the Best Regards

Érico Almeida - Graphic Designer

CNPJ: 25.246.390/0001-05

Agreement:

Company/Client: Date:

Adress:

E-mail: 


\section{Entrevista I}

Maria Fernanda Miotto Reis

Consultor Sebrae/PR

Entrevista: Como hacer un plan de marketing internacional.

1 - Entrevistador: ¿Antes de todo ¿Por qué debo hacer un plan de marketing internacional?

Entrevistada: La planificación de marketing, sea volcada al mercado interno o externo, ayuda en el control de gastos y en el registro de acciones para aumentar el número de ventas, por ejemplo. Así que independiente del tamaño de su negocio o mercado objetivo, tener un buen plan de marketing ayuda a valorar su empresa. Aunque puede parecer un poco "duro" empezar un plan de marketing de "la nada", en Sebrae tenemos una seria de herramientas, cómo guías con algunas preguntas y objetivos para ser contestados por el empresario, cuya propuesta es ayudar a obtener una visión macro del negocio y así empezar a elaborar el plan. ¡Ojo!, aunque la era digital ha acortado las distancias, la tarea de elaborar un plan de marketing internacional queda un poco más compleja. Pues tiene que llevar en cuenta también diferencias culturales, costumbres distintos, diferencias de cambio financiero, huso horario, etc.

2 - Entrevistador: ¿Es necesario responder a todas las preguntas de la propuesta del plan de marketing dispuesto por Sebrae?

Entrevistada: La verdad es que un buen plan de marketing no necesita necesariamente ser un documento extenso, y puede cambiar mucho de acuerdo con el perfil y objetivos de las empresas. Pero es esencial que el emprendedor registre sus estrategias, sus objetivos, y qué acciones han dado resultado o no. Tiene que ser claro el suficiente para contestar algunas preguntas referentes a la estrategia de ventas de su producto o servicio: ¿cómo? ¿cuándo? ¿dónde? y ¿por qué?

3 - Entrevistador: ¿Cuál es la mejor manera de empezar la elaboración del plan de marketing internacional? ¿Qué preguntas deben ser contestadas de primero? 
Entrevistada: Bueno, de primero, en todo plan de marketing, sea internacional o no,

debe hacer un buen analice del ambiente de marketing. Es decir, el primer paso es evaluar cuáles son los factores externos e internos que pueden influir en su pequeña empresa. Además, hay que analizar el segmento y el producto y ver cuáles son las capacidades del negocio. Un buen comienzo desde mi punto de vista es elaborando un análisis FODA, analizando puntos fuertes, débiles, amenazas y oportunidades de su negocio, así como del entorno competitivo, cómo el país en que pretende actuar o vender productos o servicios.

Otro punto es evaluar el capital disponible que podrá ser usado en las acciones de marketing, pues de lo contrario, el plan no tendrá sostenibilidad a largo plazo.

4 - Entrevistador: ¿Cómo determinar mi público objetivo en el plan de marketing internacional?

Entrevistada: Debe antes de todo, entender quién son sus clientes. A veces, el público objetivo de su empresa no es el consumidor. El público objetivo de una determinada marca de galletas rellenas, por ejemplo, son los niños, aunque tenga un gran número de consumidores adultos. Un plan de marketing tiene que ser dirigido al público objetivo.

El análisis del mercado también es importante, prestando atención a las demandas, en el potencial, en la previsión de tasa de crecimiento y de participación. Por lo tanto, es importante una mirada crítica en estudios y previsiones de importantes instituciones internacionales, como por ejemplo, la OMC- Organización Mundial del Comercio o instituciones gubernamentales. Se hace necesario también entender cómo, por qué y cuando los consumidores utilizan su producto o servicio. A veces la mejor investigación de mercado es la simple conversación, jsalir a la calle!, o en el caso del plan de marketing internacional, visitar a otro país, no se puede tener miedo de preguntar.

Es importante también mirar a otras empresas del sector que pueda entregar los mismos beneficios que su empresa. O sea, evaluar de manera crítica y detallada quiénes son y cuáles son los objetivos de los principales players de su mercado.

5 - Entrevistador: ¿Cómo elegir las mejores estrategias para la elaboración de mi plan de marketing internacional? 
Entrevistada: Debe ir por etapas.

Primero, es necesario establecer el objetivo del plan. Por ejemplo, si el emprendedor desea aumentar el número de ventas, necesita entender de dónde viene la facturación de sus ventas y evaluar si lo ideal es hacer que los clientes compren con más frecuencia o si la clave es buscar nuevos consumidores.

A continuación, es hora de evaluar qué medidas serán adoptadas por la empresa. Para los expertos, utilizar las redes sociales, dar descuento en el mes de cumpleaños del cliente son algunos ejemplos de acciones.

El monitoreo de la duración de cada acción, los resultados y los recursos necesarios que se utilizaron deben colocarse en el papel.

El plan de marketing no tiene fin, pues es recomendable que éste sea revisado, rehecho y actualizado con datos como número de ventas, facturación, rentabilidad, entre otros. 
Apex Brasil

Entrevista hecha por e-mail con el equipo experto en internacionalización de Apex Brasil.

Entrevista: Internacionalización: mucho más allá de las fronteras de Brasil.

1 - Entrevistador: ¿Por qué buscar negocios en otros países?

Entravistada: A pesar de los tiempos turbulentos y del dólar oscilante, cada vez más empresas brasileñas han intentado aventurarse en mercados extranjeros. Basta una rápida investigación en los noticieros para constatar que, ya sea en busca de nuevos mercados o de nuevas tecnologías, cada vez más emprendedores arreglan sus maletas y parten hacia el exterior. Según el jornal diario O Globo, el crecimiento en la internacionalización de las multinacionales brasileñas fue de 50\% en el período de 2010 para 2015.

2 - Entrevistador: ¿Qué significa exactamente la internacionalización?

Entravistada: En resumen, es el proceso que lleva a una empresa a establecer relaciones de negocios más allá de las fronteras del país en que actúa. Esas relaciones pueden ocurrir tanto a través de exportaciones de productos o servicios como de importaciones de materias primas, tecnologías y otros insumos.

El proceso requiere mucho estudio y mucho análisis. En primer lugar, debe asegurarse de que sus negocios estén en orden y que su producto o servicio ya está consolidado, con un mercado consumidor bien delineado. A continuación, asegurarse de que su empresa tenga capital de trabajo suficiente para aguantar la aventura sin entrar en crisis. ¿Qué pasa si lleva su empresa hacia fuera y quedase sin dinero para operar? Nadie quiere eso, por lo que la clave es la planificación.

3 - Entrevistador: ¿Cómo hacer un proceso de internacionalización exitoso?

Entravistada: La verdad es que hay más de un modelo para internacionalizar un negocio. 
4 - Entrevistador: Por ejemplo ¿Comprar una pequeña empresa para entrar en los

Estados Unidos tiene sentido?

Entravistada: Los Estados Unidos han sido uno de los principales destinos de emprendedores brasileños, y no es para menos: hay mucho mercado a explotar allí. En realidad, adquirir un pequeño negocio local puede ser una estrategia eficaz de internacionalización para su empresa. Allá se cuenta con bases ya estructuradas y con la experiencia de equipos locales, además de carteras de clientes y, en algunos casos, marcas ya fortalecidas.

Pero, como toda estrategia, algunos cuidados son indispensables. No importa si la empresa adquirida es micro o pequeña, el hecho de asumirla no significa que será posible imponer su cultura organizacional fácilmente, por ejemplo. Esto no se cambia de un día para otro.

5 - Entrevistador: Mi empresa proporciona servicios. ¿Cómo moldear el proceso de internacionalización?

Entravistada: Algunos cuidados son fundamentales. La primera sugerencia es construir la confianza en cada nuevo mercado localmente. Los consumidores tienden a preferir marcas que proporcionan servicios adaptados regionalmente y que se adaptan a sus necesidades. Es decir, hay que conocer las particularidades del mercado en que pretende actuar.

Se trata del proceso de "localización", que tiene el sentido de "hacer local": una aproximación multifacética de un mercado específico, lo que requiere tiempo, desarrollo y soporte.

Algunas indicaciones: crear y alojar un sitio web en un dominio local - y en la lengua nativa. En algunos casos, contratar a un profesional o asesoría que proporcione soporte en el sentido de dar feedback sobre lo que quieren y lo que no quieren los consumidores locales. Garantizar todo el soporte vía teléfono, chat o e-mail, siempre en la lengua nativa.

Contratar profesionales especializados para conferir la traducción de los sitios, para desarrollar el marketing y el branding locales, además de crear eventos y campañas también son buenas indicaciones para hacerse conocido. 
"Declaro bajo juramento que esta tesis fue elaborada por mí, que no utilicé ningún otro material que no haya dado a conocer en las referencias y que no utilicé frases o párrafos de otros autores y que este trabajo de tesis nunca ha sido presentado ante un comité de evaluación de tesis y que no transgrede derechos de terceros."

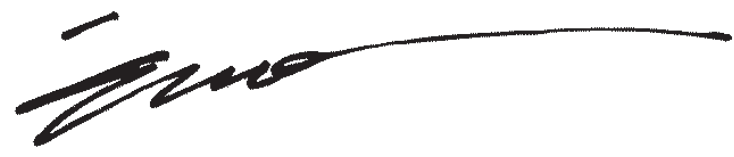

Érico Ribeiro de Almeida 